\title{
Are Constant Interest Rate Forecasts Modest Policy Interventions? Evidence from a Dynamic Open Economy Model
}

\author{
Malin Adolfson \\ Sveriges Riksbank
}

\author{
Stefan Laséen \\ Sveriges Riksbank
}

Mattias Villani*

Sveriges Riksbank and Stockholm University

September 19, 2005

\author{
Jesper Lindé
Riksbank and CEPR \\ Jesper Lindé
Sveriges Riksbank and CEPR
}

(1)

\begin{abstract}
This paper uses an estimated open economy dynamic stochastic general equilibrium model for the Euro area to examine if during 1993Q4 - 2002Q4 constant interest rate forecasts, commonly used by inflation targeting central banks, are viewed as being in line with the central bank's historical policy behavior. In the sense of Leeper and Zha (2003), a constant interest rate forecast is defined as a modest intervention of the policy rule if it does not trigger the agents to revise their expectations about the inflation targeting policy. Using univariate modesty statistics, we show that the modesty of the policy interventions depends on the assumptions about the uncertainty in the future shock realizations. Taking the joint effects of the policy interventions on all variables into consideration, we find that the constant interest rate forecasts are not modest policy interventions in the latter part of the sample $(1998 Q 4-2002 Q 4)$, and thereby affect the expectations formation of the agents. Consequently, the constant interest rate assumption has arguably lead to conditional forecasts at the two year horizon that cannot be considered economically meaningful during this period, and should not be used as a communication device by inflation targeting central banks.
\end{abstract}

Keywords: Forecasting; Monetary policy; Open economy DSGE model; Policy interventions; Bayesian inference.

JEL Classification Numbers: E47; E52; C11; C53.

\footnotetext{
*Address: Sveriges Riksbank, SE-103 37 Stockholm, Sweden. E-mails: malin.adolfson@riksbank.se, stefan.laseen@riksbank.se, jesper.linde@riksbank.se and mattias.villani@riksbank.se.

This paper was prepared for the International Finance conference "New Policy Thinking in Macroeconomics", 2004. We are grateful to our discussant Bruce Preston for many valuable comments. We would also like to thank Fabio Ghironi and an anonymous referee for helpful suggestions. The paper was written while Lindé was a visiting scholar at the Institute for International Economic Studies, Stockholm University. The views expressed in this paper are solely the responsibility of the authors and should not be interpreted as reflecting the views of the Executive Board of Sveriges Riksbank.
} 


\section{Introduction}

After the introduction of explicit inflation targets, many central banks produce two-year ahead forecasts of aggregate prices and quantities since monetary policy is thought to have delayed effects on economic activity. The rhetoric of some central banks, for example the Bank of England and Sveriges Riksbank, suggests that output and inflation forecasts are computed under the assumption that the interest rate is kept unchanged during the forecast horizon. The interest rate is then adjusted so that the inflation forecast is on target at the two-year horizon - so called constant interest rate inflation forecast targeting. However, in practice we believe that there are differences in how the forecasts actually are computed and how the central bank communicates them and their policy to the public. Both Bank of England and Sveriges Riksbank publish official forecasts in quarterly Inflation Reports. The forecasts are intended to be conditioned on the assumption of a constant interest rate, but since they are the result of many different kinds of models and also include judgments, rather than are the outcome of one single formal model, it is very difficult to ensure that these subjective forecasts really are based on a constant interest rate assumption. It could very well be that the staff take the typical policy behavior into account in the forecasts that are presented to the Executive Boards.

In practice, we therefore believe that inflation targeting central banks' conduct of monetary policy can be approximated with a policy rule in which the interest rate responds to the deviation from target of an inflation forecast based on the assumption of a constant interest rate. As the deviation of the inflation forecast from target changes with the state of the economy, this rule implies that the equilibrium interest rate changes endogenously as the conditions of the economy evolve. We label this policy rule as the CIRP rule, from 'constant interest rate policy' where the 'constant interest rate' refers to the assumption made in computing the inflation forecast that is an input in the rule. The CIRP rule is the structural description of inflation targeting central banks' behaviour in our exercise, in the sense of Lucas (1976). However, in communicating their policy, some central banks have found it convenient to describe their policy actions to the public in terms of a constant interest rate forecast (CIRF) where the interest rate is indeed kept constant during the forecast horizon. The reason for this procedure is probably that the constant interest rate forecast experiment is very intuitive and easy to understand. Moreover, such an assumption does not require the policy maker to explicitly take a stand on the future interest rate path. In a backward-looking model, where expectations formation effects are not relevant for the private sector, basing policy on the forecasts generated under a CIRP rule are equivalent to basing policy on the forecasts generated when setting the interest rate constant (i.e., CIRFs). However, this is generally not the case in a forward-looking model of the economy. In a forward-looking model the constant interest rate forecast is not an appropriate basis for the policy maker's interest rate decision, since the forward-looking agents will realize that the CIRP rule requires a different (or non-constant) interest rate as the forecast targeting span moves forward in time (see Leitemo, 2003). ${ }^{1}$ The CIRFs are, consequently, not the best description of the future expected interest rate development.

In this paper we examine whether CIRFs can be a valid communication device for a central bank which follows a CIRP. ${ }^{2}$ If a central bank bases its policy decision on a forecast that is

\footnotetext{
${ }^{1}$ To explain this more clearly, we borrow the example given in Leitemo (2003). Consider a central bank with a CIRP rule that sets the interest rate such that it, if held constant for two years, would keep the inflation forecast at the two-year horizon on target. Assume in such a setting that the three-year inflation forecast is below target, and that the central bank reconsiders its policy stance once a year. After a year has elasped in this setting, the central bank will not keep to its constant interest rate assumption but lower the interest rate such that the two-year inflation forecast again is on target, even if no new information has arrived.

${ }^{2}$ We do not think it makes sense to assume that central banks actually base their policy on CIRFs since this
} 
produced under the assumption of a constant equilibrium interest rate (as implied by CIRFs), this entails a deviation from the structural policy rule, or a policy intervention. If the policy intervention is small enough, so that it does not significantly shift the agents' beliefs about the current policy regime (i.e., the CIRP rule), the intervention is said to be modest and the CIRFs can be thought of as being structural too, and hence valid and useful to communicate policy to the public.

To examine whether constant interest rate forecasts can be characterized as modest policy interventions, we use a forward-looking open economy dynamic stochastic general equilibrium (DSGE) model estimated for the Euro area. In particular we evaluate whether constant interest rate projections are perceived as being too far away from those of the estimated historical policy rule in the model using two variants of the modesty statistic developed by Leeper and Zha (2003). The notion of a modest policy intervention is appealing since it maintains the structural modeling context but allows for a small degree of experimentation with the model. This is especially attractive in a policy context since it does not induce the changes in the agents' behavior that Lucas (1976) emphasizes. A modest policy intervention is hence a change in policy that is consistent with the historical variation in central bank behavior under the current monetary policy regime. This means that the constant interest rate forecast can very well be presented in an Inflation Report even if it implies deviating (slightly) from the historical policy behavior. A fundamental assumption in our analysis is that the central bank does not inform the agents about whether they in practice produce forecasts under the CIRP or the CIRF assumption. ${ }^{3}$

The idea behind the statistic developed by Leeper and Zha (2003) is to compare the conditional forecast under a policy intervention with the unconditional forecast. If the interventions due to the alternative policy (i.e. the conditional forecast) cause the forecasted variables to deviate largely from their unconditional forecasts, the alternative policy is not perceived as being modest. This implies that the forecasts are not 'credible', and that the formation of expectations need to be incorporated when projecting under this alternative policy. In the original framework of Leeper and Zha there is no uncertainty related to future shock realizations except for the policy shock during the conditioning period. We will, however, also consider a case where we allow for uncertainty induced by the other shocks in the model. Given that other shocks than the monetary policy shock account for a large part of the fluctuations in the system, the two cases are likely to yield different results. Once we allow for uncertainty regarding the future non-policy shocks, it is also possible to develop a multivariate generalization of the modesty statistic which accounts for the intervention effects on the joint movements of the variables.

The DSGE model used in the analysis is an open economy version of the closed economy DSGE model of Christiano, Eichenbaum and Evans (2005). As in Altig et al. (2003), we introduce a stochastic unit root technology shock, which enables us to work with trending data. Following Smets and Wouters (2003), the model is estimated with Bayesian techniques on data for the Euro area. ${ }^{4}$ We choose to use Bayesian estimation of the model parameters for several

could give rise to indeteminacy in an economy where agents are forward-looking.

${ }^{3}$ If an inflation targeting central bank credibly announced that its forecast was produced under the assumption that the equilibrium interest rate was kept constant during the forecast horizon, the agents would necessarily know that there has been a shift in the policy behavior.

${ }^{4}$ We model the Euro area as a small open economy, thereby adopting the approximating assumption that foreign inflation, output and interest rate are exogenously given. There is some empirical support for this approximation. By estimating a VAR model with ten Euro area variables and three foreign variables ("rest of the world" inflation, output and interest rate), we find that the Euro area variables account for a small fraction of the variation in the foreign variables (around 10(20) percent at the one(five) year horizon). It should be noted that also de Walque and Wouters (2004) obtain a very low estimate of the spillover effects from the Euro area to the US in their two 
reasons. First and foremost the Bayesian approach allows us to incorporate prior information about the parameters into the estimated model in a formal way. Another central feature of Bayesian inference is the unified quantification of all types of uncertainty through the use of probability. This enables a natural handling of estimation uncertainty about the parameters, as well as the model specification. It also makes it possible to obtain finite sample results in the form of whole probability distributions regarding for example impulse response functions and forecasts. Another advantage of the Bayesian approach is that the prior distribution helps to obtain numerical stability in the estimation process. For example, uninformative sections may appear in the likelihood function to high-dimensional systems such as DSGE models, and the prior distribution is used to downweight regions of the parameter space that are not relevant from an economic point of view.

DSGE models estimated with Bayesian techniques are particularly interesting to use for the type of experiment in this paper for three reasons. First, they are based on optimizing firms and households so expectations about the monetary policy regime are important. Second, Smets and Wouters (2004) have shown that large scale DSGE models, such as the one used here, are quite good descriptions of the data. They have also shown that such models have good forecasting properties compared to Bayesian VARs, which are generally considered to be very good forecasting tools. Third, and last, these models have a monetary transmission mechanism that is close in line with the conventional wisdom about the effects of monetary policy, and also well in line with the results in the identified VAR literature, see, e.g., Rotemberg and Woodford (1997), and Christiano, Eichenbaum and Evans (2005).

Our main results can be summarized as follows. According to the Leeper and Zha modesty statistics, we find that the constant interest rate forecasts are, in general, immodest in the latter part of the evaluation sample which ranges from 1993Q4 to 2002Q4. We show that bringing in uncertainty about future non-policy shock realizations makes constant interest rate forecasts more credible in general, because it gets harder for the agents to figure out to what extent the differences between the conditional and unconditional forecast is due to policy or the other shocks hitting the economy. From about 1998Q4 and onwards the modesty statistics (univariate and multivariate) indicate that the constant interest rate forecasts at the 8 quarter horizon are not in line with those obtained from the central bank's structural inflation targeting rule. The policy intervention required to generate a constant interest rate forecast is simply too large. This implies that the private sector agents will revise their expectations about monetary policy and thereby also their expectations about the overall evolution of the economy. To consider the policy experiment with a constant interest rate forecast economically meaningful in such a case, the change in the expectations formation needs to be accounted for in the model. In practice this is however difficult why we think that CIRFs should not be used for communication by inflation targeting central banks.

The first important factor for why the constant interest rate interventions are often found to be immodest during the latter part of the sample but not in the first part, is that the policy rule has changed in such a way that the effects of monetary policy shocks are relatively stronger in the end of the sample compared to the first part. The second factor are differences related to the state of the economy over the sample period. According to our model, the economy appears to be relatively far from the steady state in the latter part of the sample (e.g., the nominal interest rate is very low compared to the steady state level), which makes the constant interest rate projections less credible.

The paper is organized as follows. In Section 2, we briefly describe the theoretical open

country model. The largest effect is found on the US trade balance where the Euro area shocks account for about 15 percent at the ten year horizon. 
economy DSGE model, and report the whole sample estimation results. We present the testing framework and evaluate the conditional forecasts in Section 3. Finally, Section 4 provides some conclusions.

\section{The estimated DSGE model}

This section gives an overview of the model economy, presents the key equations in the theoretical model, and discusses how we parameterize it.

The model is an open economy version of the DSGE model in Christiano et al. (2005) and Altig et al. (2003), developed in Adolfson, Laséen, Lindé and Villani (2005). As in the closed economy setup, households maximize a utility function consisting of consumption, leisure and cash balances. However, in our open economy model the households consume a basket consisting of domestically produced goods and imported goods. These products are supplied by domestic and importing firms, respectively. We allow the imported goods to enter both aggregate consumption as well as aggregate investment. This is needed when matching the joint empirical fluctuations in both imports and consumption since imports (and investment) are a lot more volatile than consumption.

Households can save in domestic bonds and/or foreign bonds and hold cash. This choice balances into an arbitrage condition pinning down expected exchange rate changes (i.e., an uncovered interest rate parity (UIP) condition). As in the closed economy model households rent capital to the domestic firms and decide how much to invest in the capital stock given capital adjustment costs. These are costs to adjusting the investment rate as well as costs of varying the utilization rate of the capital stock. Each household is a monopoly supplier of a differentiated labour service which implies that they can set their own wage. Wage stickiness is introduced through an indexation variant of the Calvo (1983) model.

Domestic production follows a Cobb-Douglas function in capital and labour, and is exposed to stochastic technology growth as in Altig et al. (2003). The firms (domestic, importing and exporting) all produce differentiated goods and set prices according to an indexation variant of the Calvo model. By including nominal rigidities in the importing and exporting sectors we allow for short-run incomplete exchange rate pass-through to both import and export prices. ${ }^{5}$ In what follows we provide the optimization problems of the different firms and the households, and describe the behavior of the central bank.

\subsection{Model}

The model economy includes four different categories of operating firms. These are domestic goods firms, importing consumption, importing investment, and exporting firms, respectively. Within each category there is a continuum of firms that each produces a differentiated good. The domestic goods firms produce their goods out of capital and labour inputs, and sell them to a retailer which transforms the intermediate products into a homogenous final good that in turn is sold to the households. Each importing firm (consumption and investment) buys a homogenous good in the world market and converts it into a differentiated good through a brand naming technology. An import consumption packer then aggregates the differentiated import consumption goods so that the final import consumption good is a composite of these differentiated products. Likewise, the imported investment goods are aggregated by an import investment packer. The exporting firms pursue a similar scheme. They buy the domestic final

\footnotetext{
${ }^{5}$ Since there are neither any distribution costs in the import and export sectors nor an endogenous pricing to market behavior among the firms, there would be complete pass-through in the absence of nominal rigidities.
} 
good, differentiate it and send their specific product to an export packer which aggregates the different export goods before the composite is sold to the consumers in the foreign market.

The final domestic good is a composite of a continuum of $i$ differentiated goods, each supplied by a different firm, which follows the constant elasticity of substitution (CES) function

$$
Y_{t}=\left[\int_{0}^{1}\left(Y_{i, t}\right)^{\frac{1}{\lambda_{t}^{d}}} d i\right]^{\lambda_{t}^{d}}, 1 \leq \lambda_{t}^{d}<\infty
$$

where $\lambda_{t}^{d}$ is a stochastic process that determines the time-varying flexible-price markup in the domestic goods market. The demand for firm $i$ 's differentiated product, $Y_{i, t}$, follows

$$
Y_{i, t}=\left(\frac{P_{i, t}^{d}}{P_{t}^{d}}\right)^{-\frac{\lambda_{t}^{d}}{\lambda_{t}^{d}-1}} Y_{t}
$$

The domestic production is exposed to unit root technology growth as in Altig et al. (2003). The production function for intermediate good $i$ is given by

$$
Y_{i, t}=z_{t}^{1-\alpha} \epsilon_{t} K_{i, t}^{\alpha} H_{i, t}^{1-\alpha}-z_{t} \phi
$$

where $z_{t}$ is a unit-root technology shock, $\epsilon_{t}$ is a covariance stationary technology shock, and $H_{i, t}$ denotes homogeneous labour hired by the $i^{\text {th }}$ firm. Notice that $K_{i, t}$ is not the physical capital stock, but rather the capital services stock, since we allow for variable capital utilization in the model. A fixed cost $z_{t} \phi$ is included in the production function. We set this parameter so that profits are zero in steady state, following Christiano et al. (2005).

We allow for working capital by assuming that a fraction $\nu$ of the intermediate firms' wage bill has to be financed in advance through loans from a financial intermediary. Cost minimization yields the following nominal marginal cost for intermediate firm $i$ :

$$
M C_{t}^{d}=\frac{1}{(1-\alpha)^{1-\alpha}} \frac{1}{\alpha^{\alpha}}\left(R_{t}^{k}\right)^{\alpha}\left[W_{t}\left(1+\nu\left(R_{t-1}-1\right)\right)\right]^{1-\alpha} \frac{1}{\left(z_{t}\right)^{1-\alpha}} \frac{1}{\epsilon_{t}},
$$

where $R_{t}^{k}$ is the gross nominal rental rate per unit of capital services, $R_{t-1}$ the gross nominal (economy wide) interest rate, and $W_{t}$ the nominal wage rate per unit of aggregate, homogeneous, labour $H_{i, t}$.

Each of the domestic goods firms is subject to price stickiness through an indexation variant of the Calvo (1983) model. Since we have a time-varying inflation target in the model we allow for partial indexation to the current inflation target, but also to last period's inflation rate in order to allow for a lagged pricing term in the Phillips curve. Each intermediate firm faces in any period a probability $\left(1-\xi_{d}\right)$ that it can reoptimize its price. The reoptimized price is denoted $P_{t}^{d, \text { new }}{ }^{6}$ The different firms maximize profits taking into account that there might not be a chance to optimally change the price in the future. Firm $i$ therefore faces the following optimization problem when setting its price

$$
\begin{gathered}
\max _{P_{t}^{d, n e w}} \mathrm{E}_{t} \sum_{s=0}^{\infty}\left(\beta \xi_{d}\right)^{s} v_{t+s}\left[\left(\left(\pi_{t}^{d} \pi_{t+1}^{d} \ldots \pi_{t+s-1}^{d}\right)^{\kappa_{d}}\left(\bar{\pi}_{t+1}^{c} \bar{\pi}_{t+2}^{c} \ldots \bar{\pi}_{t+s}^{c}\right)^{1-\kappa_{d}} P_{t}^{d, n e w}\right) Y_{i, t+s}\right. \\
\left.-M C_{i, t+s}^{d}\left(Y_{i, t+s}+z_{t+s} \phi^{j}\right)\right]
\end{gathered}
$$

\footnotetext{
${ }^{6}$ For the firms that are not allowed to reoptimize their price, we adopt the indexation scheme $P_{t+1}^{d}=$ $\left(\pi_{t}^{d}\right)^{\kappa_{d}}\left(\bar{\pi}_{t+1}^{c}\right)^{1-\kappa_{d}} P_{t}^{d}$ where $\kappa_{d}$ is an indexation parameter.
} 
where the firm is using the stochastic household discount factor $\left(\beta \xi_{d}\right)^{s} v_{t+s}$ to make profits conditional upon utility. $\beta$ is the discount factor, and $v_{t+s}$ the marginal utility of the households' nominal income in period $t+s$, which is exogenous to the intermediate firms. $\pi_{t}^{d}$ denotes inflation in the domestic sector, $\bar{\pi}_{t}^{c}$ a time-varying inflation target of the central bank and $M C_{i, t}^{d}$ the nominal marginal cost.

The first order condition of the profit maximization problem in equation (5) yields the following log-linearized Phillips curve:

$$
\begin{aligned}
\left(\widehat{\pi}_{t}^{d}-\widehat{\bar{\pi}}_{t}^{c}\right)= & \frac{\beta}{1+\kappa_{d} \beta}\left(\mathrm{E}_{t} \widehat{\pi}_{t+1}^{d}-\rho_{\pi} \widehat{\bar{\pi}}_{t}^{c}\right)+\frac{\kappa_{d}}{1+\kappa_{d} \beta}\left(\widehat{\pi}_{t-1}^{d}-\widehat{\bar{\pi}}_{t}^{c}\right) \\
& -\frac{\kappa_{d} \beta\left(1-\rho_{\pi}\right)}{1+\kappa_{d} \beta} \widehat{\bar{\pi}}_{t}^{c}+\frac{\left(1-\xi_{d}\right)\left(1-\beta \xi_{d}\right)}{\xi_{d}\left(1+\kappa_{d} \beta\right)}\left(\widehat{m c}_{t}^{d}+\widehat{\lambda}_{t}^{d}\right),
\end{aligned}
$$

where a hat denotes log-linearized variables (i.e., $\hat{X}_{t}=d X_{t} / X$ ).

We now turn to the import and export sectors. There is a continuum of importing consumption and investment firms that buy a homogenous good at price $P_{t}^{*}$ in the world market, and differentiate this good by brand naming. The exporting firms buy the (homogenous) domestic final good at price $P_{t}^{d}$ and turn this into a differentiated export good through the same type of brand naming technology. The nominal marginal cost of the importing and exporting firms are thus $S_{t} P_{t}^{*}$ and $P_{t}^{d} / S_{t}$, respectively, where $S_{t}$ is the nominal exchange rate (domestic currency per unit of foreign currency). The differentiated import and export goods are subsequently aggregated by an import consumption, import investment and export packer, respectively, so that the final import consumption, import investment, and export good is each a CES composite according to the following:

$$
C_{t}^{m}=\left[\int_{0}^{1}\left(C_{i, t}^{m}\right)^{\frac{1}{\lambda_{t}^{m c}}} d i\right]^{\lambda_{t}^{m c}}, \quad I_{t}^{m}=\left[\int_{0}^{1}\left(I_{i, t}^{m}\right)^{\frac{1}{\lambda_{t}^{m i}}} d i\right]^{\lambda_{t}^{m i}}, \quad X_{t}=\left[\int_{0}^{1}\left(X_{i, t}\right)^{\frac{1}{\lambda_{t}^{x}}} d i\right]^{\lambda_{t}^{x}}
$$

where $1 \leq \lambda_{t}^{j}<\infty$ for $j=\{m c, m i, x\}$ is the time-varying flexible-price markup in the import consumption $(m c)$, import investment $(m i)$ and export $(x)$ sector. By assumption the continuum of consumption and investment importers invoice in the domestic currency and exporters in the foreign currency. In order to allow for short-run incomplete exchange rate pass-through to import as well as export prices we therefore introduce nominal rigidities in the local currency price, following for example Smets and Wouters (2002). This is modeled through the same type of Calvo setup as above. The price setting problems of the importing and exporting firms are completely analogous to that of the domestic firms in equation (5), and the demand for the differentiated import and export goods follow similar expressions as to equation (2). In total there are thus four specific Phillips curve relations determining inflation in the domestic, import consumption, import investment and export sectors.

In the model economy there is also a continuum of households which attain utility from consumption, leisure and real cash balances. The preferences of household $j$ are given by

$$
\mathrm{E}_{0}^{j} \sum_{t=0}^{\infty} \beta^{t}\left[\zeta_{t}^{c} \ln \left(C_{j, t}-b C_{j, t-1}\right)-\zeta_{t}^{h} A_{L} \frac{\left(h_{j, t}\right)^{1+\sigma_{L}}}{1+\sigma_{L}}+A_{q} \frac{\left(\frac{Q_{j, t}}{z_{t} P_{t}^{d}}\right)^{1-\sigma_{q}}}{1-\sigma_{q}}\right],
$$

where $C_{j, t}, h_{j, t}$ and $Q_{j, t} / P_{t}^{d}$ denote the $j^{\text {th }}$ household's levels of aggregate consumption, labour supply and real cash holdings, respectively. Consumption is subject to habit formation through 
$b C_{j, t-1}$, such that the household's marginal utility of consumption is increasing in the quantity of goods consumed last period. $\zeta_{t}^{c}$ and $\zeta_{t}^{h}$ are persistent preference shocks to consumption and labour supply, respectively. To make cash balances in equation (8) stationary when the economy is growing they are scaled by the unit root technology shock $z_{t}$. Households consume a basket of domestically produced goods and imported products which are supplied by the domestic and importing consumption firms, respectively. Aggregate consumption is assumed to be given by the following constant elasticity of substitution (CES) function:

$$
C_{t}=\left[\left(1-\omega_{c}\right)^{1 / \eta_{c}}\left(C_{t}^{d}\right)^{\left(\eta_{c}-1\right) / \eta_{c}}+\omega_{c}^{1 / \eta_{c}}\left(C_{t}^{m}\right)^{\left(\eta_{c}-1\right) / \eta_{c}}\right]^{\eta_{c} /\left(\eta_{c}-1\right)},
$$

where $C_{t}^{d}$ and $C_{t}^{m}$ are consumption of the domestic and imported good, respectively. $\omega_{c}$ is the share of imports in consumption, and $\eta_{c}$ is the elasticity of substitution across consumption goods.

The households invest in a basket of domestic and imported investment goods to form the physical capital stock, and decide how much capital services to rent to the domestic firms, given capital adjustment costs. These are costs to adjusting the investment rate as well as costs of varying the utilization rate of the physical capital stock. The households can increase their capital stock by investing in additional physical capital $\left(I_{t}\right)$, taking one period to come in action, or by directly increasing the utilization rate of the capital at hand $\left(u_{t}=K_{t} / \bar{K}_{t}\right)$. The capital accumulation equation for the physical capital stock $\left(\bar{K}_{t}\right)$ is given by

$$
\bar{K}_{t+1}=(1-\delta) \bar{K}_{t}+\Upsilon_{t}\left(1-\tilde{S}\left(I_{t} / I_{t-1}\right)\right) I_{t},
$$

where $\tilde{S}\left(I_{t} / I_{t-1}\right)$ determines the investment adjustment costs through the estimated parameter $\tilde{S}^{\prime \prime}$, and $\Upsilon_{t}$ is a stationary investment-specific technology shock. Total investment is assumed to be given by a CES aggregate of domestic and imported investment goods ( $I_{t}^{d}$ and $I_{t}^{m}$, respectively) according to

$$
I_{t}=\left[\left(1-\omega_{i}\right)^{1 / \eta_{i}}\left(I_{t}^{d}\right)^{\left(\eta_{i}-1\right) / \eta_{i}}+\omega_{i}^{1 / \eta_{i}}\left(I_{t}^{m}\right)^{\left(\eta_{i}-1\right) / \eta_{i}}\right]^{\eta_{i} /\left(\eta_{i}-1\right)},
$$

where $\omega_{i}$ is the share of imports in investment, and $\eta_{i}$ is the elasticity of substitution across investment goods.

Further, along the lines of Erceg, Henderson and Levin (2000), each household is a monopoly supplier of a differentiated labour service which implies that they can set their own wage. After having set their wage, households inelastically supply the firms' demand for labour at the going wage rate. Each household sells its labour to a firm which transforms household labour into a homogenous good that is demanded by each of the domestic goods producing firms. Wage stickiness is introduced through the Calvo (1983) setup, with partial indexation to last period's CPI inflation rate, the current inflation target and the technology growth. Household $j$ reoptimizes its nominal wage rate $W_{j, t}^{n e w}$ according to the following

$$
\begin{gathered}
\max _{W_{j, t}^{n e w}} \quad \mathrm{E}_{t} \sum_{s=0}^{\infty}\left(\beta \xi_{w}\right)^{s}\left[-\zeta_{t+s}^{h} A_{L} \frac{\left(h_{j, t+s}\right)^{1+\sigma_{L}}}{1+\sigma_{L}}+\right. \\
\left.v_{t+s} \frac{\left(1-\tau_{t+s}^{y}\right)}{\left(1+\tau_{t+s}^{w}\right)}\left(\left(\pi_{t}^{c} \ldots \pi_{t+s-1}^{c}\right)^{\kappa_{w}}\left(\bar{\pi}_{t+1}^{c} \ldots \bar{\pi}_{t+s}^{c}\right)^{\left(1-\kappa_{w}\right)}\left(\mu_{z, t+1} \ldots \mu_{z, t+s}\right) W_{j, t}^{n e w}\right) h_{j, t+s}\right],
\end{gathered}
$$


where $\xi_{w}$ is the probability that a household is not allowed to reoptimize its wage, $\tau_{t}^{y}$ a labour income tax, $\tau_{t}^{w}$ a pay-roll tax (paid for simplicity by the households), and $\mu_{z, t}=z_{t} / z_{t-1}$ is the growth rate of the permanent technology level. ${ }^{7}$

The households can accumulate capital, save in domestic and foreign bonds, and also hold cash. The choice between domestic and foreign bond holdings balances into an arbitrage condition pinning down expected exchange rate changes (i.e., an uncovered interest rate parity condition). To ensure a well-defined steady-state in the model, we assume that there is a premium on the foreign bond holdings which depends on the aggregate net foreign asset position of the domestic households, following, e.g., Lundvik (1992), and Schmitt-Grohé and Uribe (2001):

$$
\Phi\left(a_{t}, \tilde{\phi}_{t}\right)=\exp \left(-\tilde{\phi}_{a}\left(a_{t}-\bar{a}\right)+\tilde{\phi}_{t}\right),
$$

where $A_{t} \equiv\left(S_{t} B_{t}^{*}\right) /\left(P_{t} z_{t}\right)$ is the net foreign asset position, and $\tilde{\phi}_{t}$ is a shock to the risk premium. Note also that $\Phi\left(a_{t}, \tilde{\phi}_{t}\right)$ is not a 'traditional' risk premium associated to variances and covariances in a stochastic environment.

The budget constraint for the households is given by

$$
\begin{aligned}
= & M_{t+1}+S_{t} B_{t+1}^{*}+P_{t}^{c} C_{t}\left(1+\tau_{t}^{c}\right)+P_{t}^{i} I_{t}+P_{t} a\left(u_{t}\right) \bar{K}_{t} \\
& R_{t-1}\left(M_{t}-Q_{t}\right)+Q_{t}+R_{t-1}^{*} \Phi\left(a_{t-1}, \widetilde{\phi}_{t-1}\right) S_{t} B_{t}^{*} \\
& +\left(1-\tau_{t}^{k}\right) R_{t}^{k} u_{t} \bar{K}_{t}+\left(1-\tau_{t}^{y}\right) \frac{W_{t}}{1+\tau_{t}^{w}} h_{t}+\left(1-\tau_{t}^{k}\right) \Pi_{t} \\
& -\tau_{t}^{k}\left[\left(R_{t-1}-1\right)\left(M_{t}-Q_{t}\right)+\left(R_{t-1}^{*} \Phi\left(a_{t-1}, \widetilde{\phi}_{t-1}\right)-1\right) S_{t} B_{t}^{*}+B_{t}^{*}\left(S_{t}-S_{t-1}\right)\right] \\
& +T R_{t}+D_{t},
\end{aligned}
$$

where the right-hand side describes the resources at disposal. The households earn interest on the amount of nominal domestic assets that are not held as cash, $M_{t}-Q_{t}$. They can also save in foreign bonds $B_{t}^{*}$, which pay a risk-adjusted pre-tax gross interest rate of $R_{t-1}^{*} \Phi\left(a_{t-1}, \widetilde{\phi}_{t-1}\right)$. The households earn income from renting capital and labour services $\left(K_{t}\right.$ and $\left.h_{t}\right)$ to the intermediate firms, where $u_{t}$ denotes the varying capital utilization rate and $\bar{K}_{t}$ the physical capital stock. They pay taxes on consumption $\left(\tau_{t}^{c}\right)$, capital income $\left(\tau_{t}^{k}\right)$, labour income $\left(\tau_{t}^{y}\right)$, and on the payroll $\left(\tau_{t}^{w}\right) . \Pi_{t}$ denotes profits which are rebated by the firms, $T R_{t}$ are lump-sum transfers from the government, and $D_{t}$ the household's net cash income from participating in state contingent securities at time $t$. The right hand side describes how the households spend their resources on consumption and investment goods, priced at $P_{t}^{c}$ and $P_{t}^{i}$ respectively, on future bond holdings, and pay the cost of varying the capital utilization rate $P_{t} a\left(u_{t}\right) \bar{K}_{t}$, where $a\left(u_{t}\right)$ is the utilization cost function.

The central bank is assumed to follow a structural monetary policy targeting rule (CIRP) of the form

$$
\Delta R_{t}=\alpha\left[\mathrm{E}_{t}\left(\pi_{t+h} \mid R_{t+h}=\ldots=R_{t-1}, \widetilde{S}_{t}\right)-\pi^{*}\right]+\varepsilon_{R, t},
$$

where $\widetilde{S}_{t}$ is the state of the economy, and $\Delta$ denotes the first difference operator. If in period $t$ the constant interest rate inflation forecast $h$ periods ahead, $\mathrm{E}_{t}\left(\pi_{t+h} \mid R_{t+h}=\ldots=R_{t-1}, \widetilde{S}_{t}\right)$, is one percent above(below) the inflation target $\pi^{*}$, the interest rate $R_{t}$ is increased(decreased)

\footnotetext{
${ }^{7}$ For the households that are not allowed to reoptimize, the indexation scheme is $W_{j, t+1}=$ $\left(\pi_{t}^{c}\right)^{\kappa_{w}}\left(\bar{\pi}_{t+1}^{c}\right)^{\left(1-\kappa_{w}\right)} \mu_{z, t+1} W_{j, t}^{n e w}$, where $\kappa_{w}$.
} 
by $\alpha$ percent. The inclusion of an error term $\varepsilon_{R, t}$ - a monetary policy shock - reflects the conventional assumptions of errors and shocks in the implementation of monetary policy. ${ }^{8}$

The inflation forecast from a forward-looking theoretical model economy, like the one here, depends in general on the state of the economy as well as the expected policy throughout the forecast horizon (see Appendix A). Inserting this into equation (15) implies that the reduced form representation of the monetary policy rule in an inflation targeting economy is given by

$$
R_{t}=g_{\widetilde{S}}^{\prime} \widetilde{S}_{t}+g_{R} R_{t-1}+\varepsilon_{R, t},
$$

where the response coefficients $g_{\widetilde{S}}$ and $g_{R}$ depend on the structure of the theoretical model and the policy maker's preferences (i.e., how strongly the central bank reacts to constant interest rate forecast deviations from the target, $\alpha$ ), see also Honkapohja and Mitra (2004). Thus, according to the reduced form version of the policy rule, the central bank should not keep the interest rate constant throughout the forecast horizon, even if the inflation forecast in the structural framework adopts such an assumption. Set aside the impact of the monetary policy shock, the central bank should respond to all state variables and shocks (collected in $\widetilde{S}_{t}$ ) that have an effect on the inflation forecast in period $t+h$. The interest rate will then change within the forecast horizon as the inflation target span in the structural rule moves forward in time, see Leitemo (2003). Consequently, if central banks produce their forecasts in practice under the reduced form solution of the model but keep the interest rate constant, this implies deviating from the structural targeting rule (15). ${ }^{9,10}$ However, as long as this does not lead to significant changes in the private sector's expectation formation such a policy intervention is interpreted to be modest.

In the paper, we approximate the structural monetary policy with the following (log-linearized) instrument rule expressed in reduced form

$$
\begin{aligned}
\widehat{R}_{t}= & \rho_{R} \widehat{R}_{t-1}+\left(1-\rho_{R}\right)\left[\widehat{\bar{\pi}}_{t}^{c}+r_{\pi}\left(\hat{\pi}_{t-1}^{c}-\widehat{\bar{\pi}}_{t}^{c}\right)+r_{y} \hat{y}_{t-1}+r_{x} \hat{x}_{t-1}\right] \\
& +r_{\Delta \pi}\left(\hat{\pi}_{t}^{c}-\hat{\pi}_{t-1}^{c}\right)+r_{\Delta y} \Delta \hat{y}_{t}+\varepsilon_{R, t},
\end{aligned}
$$

where $\varepsilon_{R, t}$ is an uncorrelated monetary policy shock. Thus, following Smets and Wouters (2003), the central bank is assumed to adjust the short term interest rate in response to deviations of CPI inflation from the time-varying inflation target $\left(\hat{\pi}_{t-1}^{c}-\widehat{\bar{\pi}}_{t}^{c}\right)$, the output gap $\left(\hat{y}_{t-1}\right.$, measured as actual minus trend output), the real exchange rate $\left(\hat{x}_{t-1} \equiv \hat{S}_{t-1}+\hat{P}_{t-1}^{*}-\hat{P}_{t-1}^{c}\right)$ and the interest rate set in the previous period. In addition, note that the nominal interest rate adjusts directly to the inflation target. The output target used by the central bank is here defined to be the trend level of output. An alternative specification is to define the output target in terms of the level output that would have prevailed in the absence of nominal rigidities. This model consistent output gap would probably come closer to optimal monetary policy (see Woodford, 2003, for further discussion). However, Del Negro et al. (2004) show that a rule using the trend

\footnotetext{
${ }^{8}$ The policy rule could of course be extended with some measure of real economic activity, and also be generalized to convey the fact that central banks typically are concerned with the whole path of future inflation, and not just the inflation forecast of a given horizon. Honkapohja and Mitra (2004) study the properties of the rule in equation (15) in a learning framework, and find that the properties of the rule are satisfactory. If the inflation forecast is contingent on $R_{t}$ instead of $R_{t-1}$, Honkapohja and Mitra demonstrate that the rule can easily lead to indeterminacy of equilibria and instability under learning.

${ }^{9}$ In Appendix A, we discuss the relation between the CIRP inflation targeting rule (15) and the reduced form policy rule (16) in more detail.

${ }^{10}$ In a forward-looking model, the relevant forecasts for the central bank are generated by $i$ ) letting the interest rate follow the reduced form (16), ii) solve the model with (16), and iii) use the reduced form solution of the complete model to calculate the policy consistent projections.
} 
output gap is preferred over a rule with the model consistent output gap, when estimating a closed economy DSGE model on US data.

To clear the final goods market, the foreign bond market, and the loan market for working capital, the following three constraints must hold in equilibrium:

$$
\begin{gathered}
C_{t}^{d}+I_{t}^{d}+G_{t}+C_{t}^{x}+I_{t}^{x} \leq z_{t}^{1-\alpha} \epsilon_{t} K_{t}^{\alpha} H_{t}^{1-\alpha}-z_{t} \phi-a\left(u_{t}\right) \bar{K}_{t}, \\
S_{t} B_{t+1}^{*}=S_{t} P_{t}^{x}\left(C_{t}^{x}+I_{t}^{x}\right)-S_{t} P_{t}^{*}\left(C_{t}^{m}+I_{t}^{m}\right)+R_{t-1}^{*} \Phi\left(a_{t-1}, \widetilde{\phi}_{t-1}\right) S_{t} B_{t}^{*}, \\
\nu W_{t} H_{t}=\mu_{t} M_{t}-Q_{t},
\end{gathered}
$$

where $C_{t}^{x}$ and $I_{t}^{x}$ are the foreign demand for export goods, and $\mu_{t}=M_{t+1} / M_{t}$ is the monetary injection by the central bank. When defining the demand for export goods, we introduce a stationary asymmetric technology shock $\tilde{z}_{t}^{*}=z_{t}^{*} / z_{t}$, where $z_{t}^{*}$ is the permanent technology level abroad, to allow for different degrees of technological progress domestically and abroad.

The structural shock processes in the model is given in log-linearized form by the univariate representation

$$
\hat{\varsigma}_{t}=\rho_{\varsigma} \hat{\varsigma}_{t-1}+\varepsilon_{\varsigma, t}, \quad \varepsilon_{\varsigma, t} \stackrel{i i d}{\sim} N\left(0, \sigma_{\varsigma}^{2}\right)
$$

where $\varsigma_{t}=\left\{\mu_{z, t}, \epsilon_{t}, \lambda_{t}^{j}, \zeta_{t}^{c}, \zeta_{t}^{h}, \Upsilon_{t}, \tilde{\phi}_{t}, \varepsilon_{R, t}, \bar{\pi}_{t}^{c}, \tilde{z}_{t}^{*}\right\}$ and $j=\{d, m c, m i, x\}$.

Lastly, to simplify the analysis we adopt the assumption that the foreign prices, output (HP-detrended) and interest rate are exogenously given by an identified VAR model with four lags. ${ }^{11}$ The fiscal policy variables - taxes on capital income, labour income, consumption, and the pay-roll, together with (HP-detrended) government expenditures - are assumed to follow an identified VAR model with two lags. ${ }^{12}$

\subsection{Estimation}

Bayesian inference starts out from a prior distribution of all structural parameters in the model. Some parameters can be calibrated (i.e., having infinitely strict priors) whereas others can be estimated. The prior distribution reflects the available information prior to observing the data used in the estimation. Second, the joint posterior distribution of the model's parameters is obtained by updating the prior with the observed data (i.e., the likelihood function), via Bayes theorem. This conditional probability distribution given the data (i.e., the posterior distribution) may then be summarized in terms of the usual measures of location (e.g. mode and mean) and spread (e.g. standard deviation and probability intervals). The posterior mode and an approximate standard deviation, based on the inverse Hessian matrix evaluated at the mode, can be directly obtained by numerical optimization on the log of the posterior distribution. The posterior distribution is subsequently explored by generating draws using the MetropolisHastings algorithm (see Smets and Wouters (2003), and the references therein, for details).

\footnotetext{
${ }^{11}$ The reason why we include foreign output HP-detrended and not in growth rates in the VAR is that the level of foreign output enters the model (e.g., in the aggregate resource constraint). In the state-space representation of the model, which links the theoretical model to the observed data, we subsequently add the unit-root and asymmetric technology shocks to the business cycle component of foreign output in order to obtain the observed level of foreign GDP. This enables us to identify the asymmetric technology shock since the process for detrended foreign output is identified from the VAR and the process for domestic productivity from domestic quantities.

${ }^{12}$ It should be noted that Adolfson et al. (2005) report that the fiscal shocks have small dynamic effects in the model. This is because households are Ricadian and infinitively lived. Moreover, these shocks are transitory and do not generate any wealth effects. Finally, the fiscal shocks are estimated to have relatively small variance. We nevertheless keep the fiscal shocks in the analysis for two reasons. First, they reduce the degree of stochastic singularity (i.e., we can match more variables), and second, the steady state values of the fiscal variables matter for the dynamic effects of the other shocks in the model.
} 
To estimate the model we use quarterly Euro area data for the period 1970Q1-2002Q4. ${ }^{13}$ To compute the likelihood function, the model is log-linearized around the steady-state and the reduced form solution is obtained using the AIM algorithm developed by Anderson and Moore (1985). The solution is then transformed into a state-space representation mapping the unobserved state variables into the observed data. To calculate the likelihood function of the observed variables we apply the Kalman filter. ${ }^{14}$ In order to facilitate identification of the parameters and shocks we estimate, we include a large set of variables in the observed data vector, and match the following 15 variables: the domestic inflation rate $\pi_{t}$; the growth rates in consumption $\Delta c_{t}$, investment $\Delta i_{t}$, GDP $\Delta y_{t}$, exports $\Delta \widetilde{X}_{t}$, imports $\Delta \widetilde{M}_{t}$, the real wage $\Delta \bar{w}_{t}$, the consumption deflator $\pi_{t}^{d e f, c}$ and the investment deflator $\pi_{t}^{d e f, i}$; the real exchange rate $\hat{x}_{t}$; the short-run interest rate $R_{t}$; employment $\hat{E}_{t}$; foreign inflation $\pi_{t}^{*}$; the foreign interest rate $R_{t}^{*}$; and the growth rate in foreign output $\Delta y_{t}^{*}{ }^{15}$ For instance, despite the fact that the foreign variables are exogenous, we include them as observable variables as they enable identification of the asymmetric technology shock and are informative about the parameters governing the transmission of foreign impulses to the domestic economy. The reason for modeling the real variables in growth rates is that the unit root technology shock induces a stochastic trend in the levels of these variables. We estimate 13 structural shocks of which 11 follow AR(1) processes and 2 that are assumed to be identically independently distributed. In addition to these we allow for eight pre-estimated shocks provided by the exogenous fiscal and foreign VARs, which are kept fixed throughout the estimation procedure. The shocks enter in such a way that there is no stochastic singularity in the likelihood function.

We choose to calibrate those parameters which we think are weakly identified by the variables that we include in the vector of observed data. These parameters are mostly related to the steady-state values of the observed variables (i.e., the great ratios: $C / Y, I / Y$ and $G / Y) .{ }^{16}$ An alternative approach could be to include these parameters in the estimation. However, such a strategy would require a different set of variables to ensure proper identification, and would not yield different results since these parameters would simply capture the sample mean of the great ratios.

The parameters we choose to estimate pertain mostly to the nominal and real frictions in the model as well as the exogenous shock processes. Table 1 shows the assumptions for the

\footnotetext{
${ }^{13}$ The data set employed here was first constructed by Fagan et al. (2001). The Fagan data set includes foreign (i.e., rest of the world) output and inflation, but not a foreign interest rate. We therefore use the Fed funds rate as a proxy for $R_{t}^{*}$.

${ }^{14}$ We use the period $1970 Q 1-1979 Q 4$ to form a prior on the unobserved state variables in $1979 Q 4$, and then use the period 1980Q1-2002Q4 for inference.

${ }^{15}$ There is no (official) data on aggregate hours worked, $\hat{H}_{t}$, available for the euro area. Therefore, we use employment $\hat{E}_{t}$ in our estimations. Since employment is likely to respond more slowly to shocks than hours worked, we model employment using Calvo-rigidity (following Smets and Wouters, 2003): $\Delta \hat{E}_{t}=\beta \mathrm{E}_{t} \Delta \hat{E}_{t+1}+$ $\frac{\left(1-\xi_{e}\right)\left(1-\beta \xi_{e}\right)}{\xi_{e}}\left(\hat{H}_{t}-\hat{E}_{t}\right)$. For reasons discussed in greater detail in Adolfson et al. (2005), we take out a linear trend in employment and the excess trend in imports and exports relative to the trend in GDP prior to estimation.

${ }^{16}$ The calibrated parameters are set to the following: the money growth $\mu=1.01$; the discount factor $\beta=0.999$; the depreciation rate $\delta=0.013$; the capital share in production $\alpha=0.29$; the share of imports in consumption and investment $\omega_{c}=0.31$ and $\omega_{i}=0.55$, respectively; the steady-state tax rates on labour income and consumption $\tau^{y}=0.177$ and $\tau^{c}=0.125$, respectively; government expenditures-output ratio 0.20 . In addition, the persistence parameter of the inflation target is set to 0.975. For reasons discussed in greater detail in Adolfson et al. (2005), we also set the substitution elasticity between domestic and imported goods $\eta_{c}=5$ and the capital utilization parameter $\sigma_{a}=10^{6}$. The calibrated parameters, together with some of the estimated parameters (e.g. $\mu_{z}$, the steady-state growth rate) evaluated at the prior mode, imply a consumption-output ratio of 0.58 , an investmentoutput ratio of 0.22 , an import-output (and export-output) ratio of 0.25 in the steady state. Likewise, the quarterly gross interest rate $(R)$ becomes 1.013 , and the quarterly gross domestic inflation 1.005 in the steady state.
} 
prior distribution of the estimated parameters. The location of the prior distribution of the 51 estimated parameters corresponds to a large extent to those in Smets and Wouters (2003) and the findings in Altig et al. (2003) on U.S. data. For more details about our choice of prior distributions, see Adolfson et al. (2005). In Table 1 we also report the posterior mode and the approximate standard deviation.

In Figures 1a and 1b, we report the posterior mode estimates of the impulse responses from a monetary policy shock. Figure 1a displays the responses based on estimates from five sample periods with different end-of-sample period (i.e., the sample is sequentially extended from $1980 Q 1-1993 Q 4$ two year at a time up to $1980 Q 1-2001 Q 4)$. The responses appear to have changed considerably over the sample period. An almost equally sized unexpected increase in the nominal interest rate has more impact on both real and nominal variables in 1999 than in 1993. To understand why this occurs, we experiment with the parameters in the policy rule. Figure 1b displays the impulse responses using the 1993Q4 estimate of the parameters, together with the responses when we use the structural parameters from the 1993Q4 estimation but take the policy parameters from the 1999Q4 estimate. Although the structural parameters are the same, the impulse responses change dramatically when the policy rule parameters are taken from the 1999Q4 estimate. The impact of a monetary policy shock is greater in the latter case because the interest rate persistence is larger and the response to the output gap is weaker in the policy rule in 1999 than in 1993 (see Table 2). It is important to note that the changes in the impulse response functions are not due to changes in the structural or deep parameters. To see this clearly, we also plot the responses from the parametrization using the structural parameters from the 1999Q4 estimation and policy parameters from the 1993Q4 estimation. The change in the responses are very small compared to the case where all parameters come from the 1993Q4 estimation, as can be seen in Figure 1b. Differences in the responses to a monetary policy shock can thus be explained by changes in the policy parameters over the sample period.

\section{Conditional forecasts}

\subsection{Framework}

According to Leeper and Zha (2003), an intervention is modest if it "[...] does not significantly shift agents' beliefs about policy regime and does not induce the changes in behavior that Lucas (1976) emphasizes". ${ }^{17}$ The general idea behind the modesty statistic is to compare the conditional forecast (in our case the forecast generated when keeping the interest rate constant) and the unconditional forecast (i.e., the forecast induced by letting policy follow the historical behavior captured by rule (17)). The forecast is subject to uncertainty regarding which shocks will hit the economy during the forecast period, implying that there is an uncertainty interval around the median forecast. We evaluate whether constant interest rate forecasts are modest using three different statistics. First, we use the univariate modesty statistic developed by Leeper and Zha (2003) where it is assumed that no other shocks than the monetary policy shock hit the economy during the forecast period. Second, we use their univariate statistic but allow also for other shocks to hit the economy. This implies that the uncertainty intervals of the forecasts will be substantially wider, since more shocks are allowed to affect the forecasts and thereby increase the uncertainty about the future economic development. We think that allowing for all types

\footnotetext{
${ }^{17}$ Leeper and Zha (2003) use an identified VAR model whereas we use a DSGE model. However, since in both cases the reduced form is used to generate the forecasts, this is of no importance for the modesty statistic. If the policy intervention is immodest the agents are most likely going to reoptimize, and the reduced form solution of the model (VAR or DSGE) are no longer valid. That is, the Lucas critique applies even if the structural model is a DSGE model.
} 
of shock uncertainty is more natural than assuming no uncertainty about the future economy during the conditional forecasting period, given that monetary policy shocks do not account for the bulk of fluctuations in prices and quantities according to the estimated DSGE model. Third, by allowing other shocks to hit the economy, we can evaluate the conditional forecast against a multivariate modesty statistic that accounts for the effects of the conditional policy on the system as whole. ${ }^{18}$ The reason for why we think it is of interest to apply a multivariate statistic is because it will reflect that the variables can move jointly in a systematic way, which may not be captured by the univariate statistic. An implicit assumption behind the test is that the structural policy rule can change randomly, where a regime change cannot be directly observed by private agents but has to be inferred from the forecasting output of the central bank. Moreover, beliefs in the current policy regime must be firmly held by the private agents in order for the log-linear solution approximation to be accurate.

We calculate the modesty statistic as follows. Let $\varepsilon_{t}=\left(\varepsilon_{R, t}, \varepsilon_{O, t}^{\prime}\right)^{\prime}$ denote the vector of structural shocks at time $t$, where $\varepsilon_{R, t}$ is the monetary policy shock and $\varepsilon_{O, t}$ collects all the other shocks. We will consider two different approaches to generate a CIRF over the horizon $t=T+$ $1, \ldots, T+h$ by injecting a specific sequence of future monetary policy shocks $\bar{\varepsilon}_{R, T+1}, \ldots, \bar{\varepsilon}_{R, T+h}$. In the first case, it is assumed that the non-policy shocks $\varepsilon_{O, t}$ are zero throughout the conditioning period, and that the $\bar{\varepsilon}_{R^{-}}$sequence is chosen so that the interest rate is kept constant. This is the setup in Leeper-Zha (2003). We will also consider a second case, where the non-policy shocks in $\varepsilon_{O}$ are drawn from their estimated model distributions. The $\bar{\varepsilon}_{R}$-sequence is subsequently chosen conditionally on this realized $\varepsilon_{O}$-vector in order to keep the interest rate constant. The univariate modesty statistic at time $T$ for variable $y_{i}$ at horizon $h$ is defined as

$$
M_{i, T}^{h}(\bar{\varepsilon}) \equiv \frac{y_{i, T+h}(\bar{\varepsilon})-\hat{y}_{i, T+h \mid T}}{\operatorname{Std}\left[y_{i, T+h}(\varepsilon)\right]}
$$

where $\hat{y}_{i, T+h \mid T}=\mathrm{E}_{T}\left(y_{i, T+h}\right)$ is the usual no-intervention (CIRP) forecast produced at time $T$ (both the unconditional and the conditional projections are based on the median of the forecast distribution). $y_{i, T+h}(\bar{\varepsilon})$ is the realization of $y_{i}$ at time $T+h$ if the structural shocks over the intervention period equal $\bar{\varepsilon}=\left\{\bar{\varepsilon}_{R, t}, \varepsilon_{O, t}\right\}_{t=T}^{T+h}$, where $\left\{\varepsilon_{O, t}\right\}_{t=T}^{T+h}=0$ in our first case. Std denotes standard deviation. $M_{i, T}^{h}(\varepsilon)$ follows a normal distribution with zero mean and unit variance if the $\varepsilon$-sequence is drawn from the no-intervention distribution. To signal an intervention as immodest for variable $y_{i}$ at horizon $h$, Leeper and Zha (2003) therefore advocate that the absolute value of the univariate statistic should be larger than two (i.e., $\left|M_{i, T}^{h}(\bar{\varepsilon})\right|>2$ ). Expressions of $M_{i, T}^{h}(\bar{\varepsilon})$ are given in Appendix B, both with and without non-policy shocks.

The multivariate modesty statistic, in turn, measures the intervention effects on all variables' forecasts taken together. A natural multivariate generalization of the modesty statistic may then be based on

$$
M_{T}^{h}(\bar{\varepsilon}) \equiv\left[y_{T+h}(\bar{\varepsilon})-\hat{y}_{T+h \mid T}\right]^{\prime} \Omega_{T+h}^{-1}\left[y_{T+h}(\bar{\varepsilon})-\hat{y}_{T+h \mid T}\right],
$$

where $\Omega_{T+h}=\operatorname{Cov}\left[y_{T+h}(\varepsilon)\right]$. Since $y_{T+h}$ is multivariate normally distributed it follows that the distribution of $M_{T}^{h}(\varepsilon)$ under no intervention is a chi-squared distribution with $p$ degrees of freedom, where $p$ is the number of observed variables in the system. Thus, if $M_{T}^{h}(\bar{\varepsilon})$ lies far out in the right tail of the $\chi_{p}$ distribution we may say that the intervention $\bar{\varepsilon}$ is immodest. Rather than using a certain quantile of the $\chi_{p}$ distribution as a cut-off value (which varies with $p$ ), we

\footnotetext{
${ }^{18}$ We produce forecasts using the posterior mode estimates of the parameters. One could also allow for parameter uncertainty, measurement errors and uncertainty about the current state, but we assume that agents operating in this economy, as well as the central bank, do not suffer from these sources of uncertainty. However, these sources of forecast uncertainty are small compared to uncertainty about future realizations of the shocks.
} 
will use the tail probability $\operatorname{Pr}\left[M_{T}^{h}(\varepsilon) \geq M_{T}^{h}(\bar{\varepsilon})\right]$ to determine whether or not an intervention is modest. A small probability, say below 0.05 , signals an immodest intervention. It should be noted that the unexpected movements of the variables in the original Leeper-Zha framework are linearly dependent and $\Omega_{T+h}$ is singular. The multivariate statistic therefore only makes sense if non-policy shocks are allowed to be non-zero in the conditioning period. For more details, see Appendix B.

\subsection{Results}

Figure $2 \mathrm{a}$ and $2 \mathrm{~b}$ show the univariate modesty statistic for the twelve domestic variables at 4 and 8 quarters horizon, when the forecast is conditioned on a constant interest rate. Note that we do not include the interest rate in the computation of the statistics, since a key assumption in our analysis is that the agents do not observe which interest rate path the forecast is conditioned upon. In Figure 2a we report the modesty statistic when no other shocks than the monetary policy shock hit the economy during the conditioning period (i.e., the original Leeper-Zha statistic). The Leeper-Zha statistic indicates that the constant interest rate interventions are immodest for almost all variables at 4 quarters horizon during 1998Q4 to 2001Q1. This implies that the private sector would not perceive the constant interest rate forecasts to be consistent with the structural targeting rule, the policy intervention is too large to be considered in line with the historical policy behavior. Thus, if the central bank for some reason decided to base and communicate their interest rate decision on the constant interest rate forecast in this case, the Lucas critique would apply and the agents would necessarily revise their expectations about the future monetary policy. This would make the forecast irrelevant. At the 8 quarter horizon the immodesty signal is even stronger. Here the statistic marks the constant interest rate intervention as immodest from 1998Q4 and onwards, for all variables except imports. Hence, constant interest forecasts are not meaningful to carry out in the latter part of the sample, according to the Leeper-Zha statistic.

Remember though that the monetary policy shocks are the only disturbances the agents perceive in the previous case. In Figure $2 \mathrm{~b}$ we allow also for other shocks during the two year conditioning period. Allowing for uncertainty about the future economy naturally makes the agents more uncertain about the central bank's policy interventions, which in turn increases the denominator in the modesty statistic (see equation 21). Consequently, the conditional interventions are in many more periods considered to be modest compared to when no other shocks are allowed. At the four quarter horizon all of the variables indicate modest interventions (see Figure 2b). At the eight quarter horizon, however, the inflation series (both domestic and the consumption and investment deflators), employment, and output forecasts seem to display immodest interventions in 1999Q1-1999Q3. The inflation forecasts also indicate immodest interventions in 1999 Q4.

To understand the differences between the two univariate modesty statistics (with and without non-policy shocks), Figures 3 and 4 depict the actual forecasts under a constant interest rate, where monetary policy shocks have been injected to keep the interest rate invariable. Figures 3a and 3b show the unconditional and conditional forecasts when standing in 1999Q2, with monetary policy shock uncertainty only and with uncertainty about all shocks, respectively. Figures $4 \mathrm{a}$ and $4 \mathrm{~b}$ report the same forecasts when standing in 2001Q1. We choose these two occasions since the two univariate modesty statistics both label the CIRFs in 1999Q2 as immodest policy interventions, but classifies the CIRFs in 2001Q1 differently depending on the assumption made about future shock uncertainty. The figures display the median forecasts and the $95 \%$ forecast intervals for the domestic variables. The unconditional forecast is depicted in grey and with a 
solid line, and the conditional forecast is depicted by dashed lines. Note that the interest rate is included in the figures but not in the computation of the modesty statistics. This is done in order to provide information about the size of the policy intervention. ${ }^{19}$

In 1999 Q2, the two univariate statistics both indicate immodest interventions. By comparing Figures $3 \mathrm{a}$ and $3 \mathrm{~b}$, we see that the uncertainty bands of the forecasts are much smaller when only monetary policy shocks hit the economy during the conditioning period (i.e., the LeeperZha case). In the case when only monetary policy shocks are allowed to hit the economy, the agents can therefore make better inference about the policy maker's behavior and the LeeperZha statistic give a strong indication of immodesty. In the case where the agents are uncertain about all shocks in the economy, the forecasts conditioned on a constant interest rate do not lie outside of the unconditional forecast (i.e., the grey area) to the same extent, which is the reason why the modesty statistic in this case indicates that the policy intervention is modest.

Figure 2c shows the $p$-values of the multivariate modesty statistic for all variables (except the interest rate) and for the subset consisting of CPI inflation and output. The general picture is that by taking the joint effects of the conditional forecasts into account, more interventions are labeled as immodest (i.e., less credible). For example, at eight quarters horizon the univariate statistic labels the policy intervention as modest for all variables during 2000 and 2001, while its multivariate counterpart signals immodesty at almost every quarter during the same period, at least the statistic which includes all variables except the interest rate.

The differing conclusions from the univariate and the multivariate modesty statistics is explained partly by the accumulated effect of having several variables not too far from the critical region of the univariate modesty statistic, but also by the correlation between variables in the joint forecast distribution. Conditional forecasts of individual variables may not be very extreme in reference to the univariate unconditional forecast distributions, but the conditional forecasts of two or more variables may 'go against' the correlation structure in the joint unconditional forecast distribution and therefore easily end up in regions of low probability. That is, the forecast paths of two variables may individually not be perceived as implausible by the agents, but observing the two paths simultaneously may very well be. A comparison of univariate and bivariate forecast distributions for all pairs of variables shows that this is indeed the case here (details available from the authors by request). The intervention's effect on the joint movements of the variables, as captured by the multivariate statistic, may thus be crucial for assessing the modesty of an intervention.

\section{Concluding remarks}

Our starting point in this paper is that monetary policy in many countries can be described by a constant interest rate inflation targeting (CIRP) rule of the type presented in equation (15). Given this, one important insight is that in forward-looking models, the constant interest rate inflation targeting rule does not imply that the forecasts should be computed with a constant interest rate in practice. As noted by Leitemo (2003) and Honkapohja and Mitra (2004), a constant interest rate forecast is not compatible with a CIRP rule in a forward-looking model because private agents update their expectations about policy during the forecast horizon.

Some central banks say, nonetheless, that they actually compute forecasts keeping the interest rate constant, which seems inconsistent with the constant interest rate targeting rule they claim they have adopted. It is, however, unclear how the constant interest rate forecasts (CIRF) are

\footnotetext{
${ }^{19}$ The figures also display the evolution of the economy after the conditioning period (i.e., after eight quarters) when the interest rate is again assumed to follow the estimated rule. This allows us to study the impact of the constant interest rate forecast at longer horizons.
} 
used in the interest rate decision process and to what extent central banks base their Inflation Reports on CIRF or on letting the interest rate follow the reduced form policy rule implied by constant interest rate inflation targeting. This paper has therefore dealt with the following question: would private agents perceive constant interest rate forecasts to be in line with the historical policy (i.e., the CIRP rule)? The tool in our investigation was an estimated open economy DSGE model which was used to examine if CIRFs were modest policy interventions in the sense that they would not have given rise to private agents changing their perceptions about the structural monetary policy rule, following the framework in Leeper and Zha (2003).

Looking at the forecasts of inflation and output up to the eight quarter horizon is particularly interesting since these are the two most important variables communicated in central banks' Inflation Reports. For these two variables, our main findings are that constant interest rate forecasts were not modest policy interventions during most of $1999-2002$ for the Euro area at the eight quarter horizon. For a larger set of macroeconomic variables, the results speak even more against the use of CIRFs. Hence, if the ECB in a given period considered basing its policy decisions on CIRFs rather than on forecasts generated by their normal policy action, it would be running the risk of triggering changes in private sector expectations about its monetary policy strategy. Our interpretation of these results is therefore that constant interest rate forecasts are not a useful communication device of CIRP rules. Although CIRFs are not always immodest policy interventions, we nevertheless believe it is not appropriate for central banks to alter their communication strategy about their monetary policy decisions from period to period. In light of this, it is not surprising that some former constant interest rate inflation forecast targeting central banks (for example, the Bank of England and Sveriges Riksbank) are today reconsidering the role of CIRFs and are moving towards forecasts that account for the private agents' perceptions of the future interest rate. 


\section{Appendix A. Constant interest rate policy rules in forward-looking models}

To understand why CIRP rules imply a systematic change of the interest rate during the forecast horizon in a forward-looking model, the reduced form policy rule is derived in this appendix. The DSGE model can be written on matrix form as

$$
\begin{aligned}
A_{0} \widetilde{Y}_{t} & =A_{1} \mathrm{E}_{t} \widetilde{Y}_{t+1}+B_{0} \theta_{t}+C \mathrm{E}_{t} \widetilde{R}_{t+1}, \\
\theta_{t} & =\rho \theta_{t-1}+\varepsilon_{t},
\end{aligned}
$$

where $\widetilde{Y}_{t}$ is a $n_{Y} \times 1$ vector of the endogenous variables in the theoretical model (contemporaneous and lagged), $\theta_{t}$ is a vector of exogenous variables, and $\widetilde{R}_{t+1}=\left(R_{t+1}, R_{t}, R_{t-1}\right)^{\prime}$. Finally, the model is closed by the inflation targeting rule in (15).

To derive the reduced form, we need to compute $\mathrm{E}_{t}\left(\pi_{t+h} \mid R_{t+h}=\ldots=R_{t-1}, \widetilde{S}_{t}\right)-\pi^{*}$, where $\widetilde{S}_{t} \equiv\left(\widetilde{Y}_{t}, \theta_{t}\right)^{\prime}$. Without loss of generality, we here assume that $\pi^{*}=0$. Assuming that $A_{0}$ is invertible, iterating forward $h$ periods implies

$$
\widetilde{Y}_{t}=\widetilde{A}_{1}^{h} \mathrm{E}_{t} \widetilde{Y}_{t+h}+\sum_{j=0}^{h-1} \widetilde{A}_{1}^{j} \widetilde{B}_{0} \rho^{j} \theta_{t}+\sum_{j=0}^{h-1} \widetilde{A}_{1}^{j} \widetilde{C} \mathrm{E}_{t} \widetilde{R}_{t+1+j},
$$

where $\widetilde{A}_{1}=A_{0}^{-1} A_{1}, \widetilde{B}_{0}=A_{0}^{-1} B_{0}$, and $\widetilde{C}=A_{0}^{-1} C$. Notice that $\widetilde{A}_{1}^{0}$ and $\rho^{0}$ are identity matrices. Equation (A.2) can be rearranged as

$$
\mathrm{E}_{t} \widetilde{Y}_{t+h}=\widetilde{A}_{1}^{-h}\left(\widetilde{Y}_{t}-\sum_{j=0}^{h-1} \widetilde{A}_{1}^{j} \widetilde{B}_{0} \rho^{j} \theta_{t}-\sum_{j=0}^{h-1} \widetilde{A}_{1}^{j} \widetilde{C} \mathrm{E}_{t} \widetilde{R}_{t+1+j}\right),
$$

provided that $\widetilde{A}_{1}^{-h}$ exists. Equation (A.3) shows that $\mathrm{E}_{t} \widetilde{Y}_{t+h}$ depends on the state of the economy, $\widetilde{S}_{t}$, as well as expectations about current and future monetary policy.

Assuming that the interest rate is kept equal to $R_{t-1}$ during the forecasting horizon $t+$ $1, \ldots t+h$, we have that $\widetilde{R}_{t+h}=\ldots=\widetilde{R}_{t}=\left(R_{t-1}, R_{t-1}, R_{t-1}\right)^{\prime}$, which implies that (A.3) can be rewritten as

$$
\mathrm{E}_{t}\left(\widetilde{Y}_{t+h} \mid R_{t+h}=\ldots=R_{t-1}, \widetilde{S}_{t}\right)=S_{Y}(h) \widetilde{Y}_{t}-S_{\theta}(h) \theta_{t}-S_{R}(h) R_{t-1},
$$

where $S_{Y}(h) \equiv \widetilde{A}_{1}^{-h}, S_{\theta}(h) \equiv S_{Y}(h) \sum_{j=0}^{h-1} \widetilde{A}_{1}^{j} \widetilde{B}_{0} \rho^{j}$, and $S_{R}(h) \equiv S_{Y}(h) \sum_{j=0}^{h-1} \widetilde{A}_{1}^{j} \widetilde{C} \iota, \iota=(1,1,1)^{\prime}$.

To obtain the reduced form policy rule in equation (16) of the main text, we insert (A.4) into the structural policy rule, and by defining

$$
\begin{aligned}
g_{\widetilde{S}} & \equiv\left(S_{Y}(h),-S_{\theta}(h)\right)^{\prime} \tilde{\alpha}, \\
g_{R} & \equiv 1-\tilde{\alpha}^{\prime} S_{R}(h),
\end{aligned}
$$

where $\tilde{\alpha} \equiv(0, \ldots, \alpha, \ldots, 0)^{\prime}$ is a $n_{Y} \times 1$ vector with zeros except in the location of $\pi_{t}$ in $\tilde{Y}_{t}$, we have equation (16).

Finally, the reduced-form solution of the model that are used for forecasting purposes, are obtained by solving (A.1) and (16) using standard methods (e.g., the Anderson and Moore (1985) algorithm). 


\section{Appendix B. Statistics for modest interventions in state space models}

This appendix details the implementation of the three modesty statistics discussed in the text in the state-space model

$$
\begin{aligned}
& \xi_{t}=F \xi_{t-1}+B \varepsilon_{t} \\
& y_{t}=A^{\prime} x_{t}+H^{\prime} \xi_{t}+w_{t}
\end{aligned}
$$

where $\xi_{t}$ is the partially unobserved vector of state variables and $y_{t}$ is a $p$-dimensional vector of observed variables. The innovation sequence $\{\varepsilon\}_{t=1}^{T}$ and the measurement errors $\left\{w_{t}\right\}_{t=1}^{T}$ are assumed to be iid multivariate normal processes with zero mean and $\operatorname{Cov}\left(w_{t}\right)=R$ and $\operatorname{Cov}\left(\varepsilon_{t}\right)=\Sigma_{\varepsilon}$, respectively. See, e.g., Hamilton (1994, Ch. 13) for details.

We will first treat the univariate and multivariate modesty statistics in (21) and (22) in the case where all shocks are allowed during the conditioning period. We then move on to the univariate Leeper-Zha modesty statistic, with only monetary policy shocks. In order to compute the modesty statistics we need expressions for $\hat{y}_{T+h \mid T}=\mathrm{E}_{T}\left(y_{T+h}\right)$, the baseline forecast, and $\Omega_{T+h}=\operatorname{Cov}\left[y_{T+h}(\varepsilon)\right]$, the covariance matrix of $y_{T+h}$ when the shocks are drawn from the model distributions. Note first that

$$
\hat{y}_{T+h \mid T}=A^{\prime} x_{T+h}+H^{\prime} E_{T}\left(\xi_{T+h}\right),
$$

where $\mathrm{E}_{T}\left(\xi_{T+h}\right)=F^{h} \hat{\xi}_{T \mid T}$ and $\hat{\xi}_{T \mid T}=\mathrm{E}_{T}\left(\hat{\xi}_{T}\right)$ is obtained from the Kalman filter (Hamilton, 1994, Ch. 13). Thus,

$$
y_{T+h}-\hat{y}_{T+h \mid T}=H^{\prime}\left(\xi_{T+h}-F^{h} \hat{\xi}_{T \mid T}\right)+w_{T+h},
$$

and

$$
\Omega_{T+h}=H^{\prime} P_{T+h \mid T} H+R .
$$

$P_{T+h \mid T}$ is obtained from the recursion

$$
P_{T+i \mid T}=F P_{T+i-1 \mid T} F^{\prime}+B \Sigma_{\varepsilon} B^{\prime},
$$

where, under the assumption that the agents observe the past history of $\xi_{t}, P_{T \mid T}$ is the zero matrix.

If we assume that all shocks other than the monetary policy shock are zero as in Leeper and Zha (2003), the above formulae still applies if we replace the recursion for $P_{T+i \mid T}$ with

$$
P_{T+i \mid T}=F P_{T+i-1 \mid T} F^{\prime}+\sigma_{\varepsilon_{1}}^{2} B_{1} B_{1}^{\prime},
$$

where $\sigma_{\varepsilon_{1}}^{2}$ is the variance of the monetary policy shocks and $B_{1}$ is the first column of $B$ (assuming the monetary policy shock to be first shock in $\left.\varepsilon_{t}\right)$. Note that $\operatorname{rank}\left(P_{T+i \mid T}\right)=i$, for $i \geq 0$. This in turn implies that $\Omega_{T+h}$ has rank $h$ and therefore that $\Omega_{T+h}$ is singular for all horizons $h$ smaller than the number variables in $y_{t}$. Thus, with only a single shock to drive the system, the unexpected movements in the variables are linearly dependent and the multivariate modesty statistic makes no sense. 


\section{References}

Adolfson, Malin, Stefan Laséen, Jesper Lindé and Mattias Villani (2005), "Bayesian Estimation of an Open Economy DSGE Model with Incomplete Pass-Through", Working Paper No. 179, Sveriges Riksbank.

Altig, David, Lawrence Christiano, Martin Eichenbaum and Jesper Lindé (2003), "The Role of Monetary Policy in the Propagation of Technology Shocks", manuscript, Northwestern University.

Anderson, Gary and George Moore (1985), "A Linear Algebraic Procedure for Solving Linear Perfect Foresight Models", Economics Letters 17(3), 247-252.

Calvo, Guillermo (1983), "Staggered Prices in a Utility Maximizing Framework", Journal of Monetary Economics 12, 383-398.

Christiano, Lawrence, Martin Eichenbaum and Charles Evans (2005), "Nominal Rigidities and the Dynamic Effects of a Shock to Monetary Policy", Journal of Political Economy, forthcoming.

Del Negro, Marco, Frank Schorfheide, Frank Smets and Raf Wouters (2004), "On the Fit and Forecasting Performance of New Keynesian Models", Working Paper No. 37, Federal Reserve Bank of Atlanta.

Erceg, Christopher, Dale Henderson and Andrew Levin (2000), "Optimal Monetary Policy with Staggered Wage and Price Contracts", Journal of Monetary Economics 46(2), 281-313.

Fagan, Gabriel, Jerome Henry and Ricardo Mestre (2001), "An Area-Wide Model (AWM) for the Euro Area", Working Paper No. 42. European Central Bank.

Hamilton, James (1994), Time Series Analysis, Princeton University Press, Princeton.

Honkapohja, Seppo and Kaushik Mitra (2004), "Performance of Inflation Targeting Based On Constant Interest Rate Projections", manuscript (June 2, 2004, revised version), University of Cambridge.

Leeper, Eric and Tao Zha (2003), "Modest Policy Interventions", Journal of Monetary Economics 50(8), 1673-1700.

Leitemo, Kai (2003), "Targeting Inflation by Constant-Interest-Rate Forecasts", Journal of Money, Credit, and Banking, 35(4), 609-626.

Lundvik, Petter (1992), "Foreign Demand and Domestic Business Cycles: Sweden 1891-1987", Chapter 3 in Business Cycles and Growth, Monograph Series No. 22, Institute for International Economic Studies, Stockholm University.

Lucas, Robert (1976), "Econometric Policy Evaluation: A Critique", Carnegie-Rochester Conference Series on Public Policy 1, 19-46.

Rotemberg, Julio and Michael Woodford (1997), "An Optimization-Based Econometric Model for the Evaluation of Monetary Policy", NBER Macroeconomics Annual 12, 297-346.

Schmitt-Grohé Stephanie and Martín Uribe (2001), "Stabilization Policy and the Costs of Dollarization", Journal of Money, Credit, and Banking 33(2), 482-509. 
Smets, Frank and Raf Wouters (2002), "Openness, Imperfect Exchange Rate Pass-Through and Monetary Policy", Journal of Monetary Economics 49(5), 913-940.

Smets, Frank and Raf Wouters (2003), "An Estimated Stochastic Dynamic General Equilibrium Model of the Euro Area", Journal of the European Economic Association, 1(5), 1123-1175.

Smets, Frank and Raf Wouters (2004), "Forecasting with a Bayesian DSGE Model. An Application to the Euro Area", Working Paper No. 389, European Central Bank.

Walque, Grégory de and Raf Wouters (2004), "An Open Economy DSGE Model Linking the Euro Area and the US Economy", manuscript, National Bank of Belgium.

Woodford, Michael (2003), Interest and Prices: Foundations of a Theory of Monetary Policy, Princeton University Press, Princeton. 
Table 1: Prior and posterior distributions

\begin{tabular}{|c|c|c|c|c|c|c|c|c|c|}
\hline \multirow[t]{2}{*}{ Parameter } & & \multicolumn{3}{|c|}{ Prior distribution } & \multicolumn{5}{|c|}{$\begin{array}{c}\text { Sample period 1980Q1-2002Q4 } \\
\text { Posterior distribution }\end{array}$} \\
\hline & & type & mean $^{*}$ & $\begin{array}{c}\text { std.dev. } \\
\text { /df }\end{array}$ & mode & $\begin{array}{l}\text { std. dev. } \\
\text { (Hessian) }\end{array}$ & mean & $5 \%$ & $95 \%$ \\
\hline Calvo wages & $\xi_{w}$ & beta & 0.675 & 0.050 & 0.697 & 0.047 & 0.690 & 0.607 & 0.766 \\
\hline Calvo domestic prices & $\xi_{d}$ & beta & 0.675 & 0.050 & 0.883 & 0.015 & 0.891 & 0.862 & 0.921 \\
\hline Calvo import cons. prices & $\xi_{m c}$ & beta & 0.500 & 0.100 & 0.463 & 0.059 & 0.444 & 0.345 & 0.540 \\
\hline Calvo import inv. prices & $\xi_{m i}$ & beta & 0.500 & 0.100 & 0.740 & 0.040 & 0.721 & 0.641 & 0.792 \\
\hline Calvo export prices & $\xi_{x}$ & beta & 0.500 & 0.100 & 0.639 & 0.059 & 0.612 & 0.506 & 0.717 \\
\hline Calvo employment & $\xi_{e}$ & beta & 0.675 & 0.100 & 0.792 & 0.022 & 0.787 & 0.741 & 0.827 \\
\hline Indexation wages & $\kappa_{w}$ & beta & 0.500 & 0.150 & 0.516 & 0.160 & 0.497 & 0.258 & 0.739 \\
\hline Indexation domestic prices & $\kappa_{d}$ & beta & 0.500 & 0.150 & 0.212 & 0.066 & 0.217 & 0.095 & 0.362 \\
\hline Index..import cons. prices & $\kappa_{m c}$ & beta & 0.500 & 0.150 & 0.161 & 0.074 & 0.220 & 0.084 & 0.418 \\
\hline Index..import inv. prices & $\kappa_{m i}$ & beta & 0.500 & 0.150 & 0.187 & 0.079 & 0.231 & 0.098 & 0.405 \\
\hline Indexation export prices & $\kappa_{x}$ & beta & 0.500 & 0.150 & 0.139 & 0.072 & 0.185 & 0.069 & 0.347 \\
\hline Markup domestic & $\lambda^{d}$ & inv. gamma & 1.200 & 2 & 1.168 & 0.053 & 1.222 & 1.122 & 1.383 \\
\hline Markup imported cons. & $\lambda^{m c}$ & inv. gamma & 1.200 & 2 & 1.619 & 0.063 & 1.633 & 1.526 & 1.751 \\
\hline Markupimported invest. & $\lambda^{m i}$ & inv. gamma & 1.200 & 2 & 1.226 & 0.088 & 1.275 & 1.146 & 1.467 \\
\hline Investment adj. cost & $\widetilde{S}^{\prime \prime}$ & normal & 7.694 & 1.500 & 8.732 & 1.370 & 8.670 & 6.368 & 10.958 \\
\hline Habit formation & $b$ & beta & 0.650 & 0.100 & 0.690 & 0.048 & 0.708 & 0.608 & 0.842 \\
\hline Subst. elasticity invest. & $\eta_{i}$ & inv. gamma & 1.500 & 4 & 1.669 & 0.273 & 1.696 & 1.393 & 2.142 \\
\hline Subst. elasticity foreign & $\eta_{f}$ & inv. gamma & 1.500 & 4 & 1.460 & 0.098 & 1.486 & 1.340 & 1.674 \\
\hline Technology growth & $\mu_{z}$ & trunc. normal & 1.006 & 0.0005 & 1.005 & 0.000 & 1.005 & 1.004 & 1.006 \\
\hline Capital income tax & $\tau_{k}$ & beta & 0.120 & 0.050 & 0.137 & 0.042 & 0.135 & 0.072 & 0.200 \\
\hline Labour pay-roll tax & $\tau_{w}$ & beta & 0.200 & 0.050 & 0.186 & 0.050 & 0.197 & 0.118 & 0.286 \\
\hline Risk premium & $\tilde{\phi}$ & inv. gamma & 0.010 & 2 & 0.145 & 0.047 & 0.252 & 0.139 & 0.407 \\
\hline Unit root tech. shock & $\rho_{\mu_{z}}$ & beta & 0.850 & 0.100 & 0.723 & 0.106 & 0.698 & 0.526 & 0.852 \\
\hline Stationary tech. shock & $\rho_{\varepsilon}$ & beta & 0.850 & 0.100 & 0.909 & 0.030 & 0.886 & 0.810 & 0.939 \\
\hline Invest. spec. tech shock & $\rho_{\mathrm{Y}}$ & beta & 0.850 & 0.100 & 0.750 & 0.041 & 0.720 & 0.638 & 0.796 \\
\hline Asymmetric tech. shock & $\rho_{\tilde{z}^{*}}$ & beta & 0.850 & 0.100 & 0.993 & 0.002 & 0.992 & 0.986 & 0.995 \\
\hline Consumption pref. shock & $\rho_{\zeta^{c}}$ & beta & 0.850 & 0.100 & 0.935 & 0.029 & 0.892 & 0.722 & 0.964 \\
\hline Labour supply shock & $\rho_{\zeta^{h}}$ & beta & 0.850 & 0.100 & 0.675 & 0.062 & 0.676 & 0.565 & 0.774 \\
\hline Risk premium shock & $\rho_{\widetilde{\phi}}$ & beta & 0.850 & 0.100 & 0.991 & 0.008 & 0.955 & 0.922 & 0.991 \\
\hline Imp. cons. markup shock & $\rho_{\lambda^{m c}}$ & beta & 0.850 & 0.100 & 0.978 & 0.016 & 0.970 & 0.943 & 0.991 \\
\hline Imp. invest. markup shock & $\rho_{\lambda^{m i}}$ & beta & 0.850 & 0.100 & 0.974 & 0.015 & 0.963 & 0.931 & 0.989 \\
\hline Export markup shock & $\rho_{\lambda^{x}-}$ & beta & 0.850 & 0.100 & 0.894 & 0.045 & 0.886 & 0.789 & 0.961 \\
\hline Unit root tech. shock & $\sigma_{z}$ & inv. gamma & 0.200 & 2 & 0.130 & 0.025 & 0.137 & 0.099 & 0.185 \\
\hline Stationary tech. shock & $\sigma_{\varepsilon}$ & inv. gamma & 0.700 & 2 & 0.452 & 0.082 & 0.519 & 0.361 & 0.756 \\
\hline Invest. spec. tech. shock & $\sigma_{\mathrm{Y}}$ & inv. gamma & 0.200 & 2 & 0.424 & 0.046 & 0.469 & 0.389 & 0.561 \\
\hline Asymmetric tech. shock & $\sigma_{\tilde{z}^{*}}$ & inv. gamma & 0.200 & 2 & 0.203 & 0.031 & 0.217 & 0.166 & 0.276 \\
\hline Consumption pref. shock & $\sigma_{\zeta^{c}}$ & inv. gamma & 0.200 & 2 & 0.151 & 0.031 & 0.157 & 0.108 & 0.224 \\
\hline Labour supply shock & $\sigma_{\zeta^{h}}$ & inv. gamma & 0.050 & 2 & 0.095 & 0.015 & 0.098 & 0.075 & 0.128 \\
\hline Risk premium shock & $\sigma_{\widetilde{\phi}}$ & inv. gamma & 0.400 & 2 & 0.130 & 0.023 & 0.183 & 0.128 & 0.246 \\
\hline Domestic markup shock & $\sigma_{\lambda^{d}}$ & inv. gamma & 0.300 & 2 & 0.130 & 0.012 & 0.132 & 0.111 & 0.157 \\
\hline Imp. cons. markup shock & $\sigma_{\lambda^{m c}}$ & inv. gamma & 0.300 & 2 & 2.548 & 0.710 & 2.882 & 1.737 & 4.463 \\
\hline Imp. invest. markup shock & $\sigma_{\lambda^{m i}}$ & inv. gamma & 0.300 & 2 & 0.292 & 0.079 & 0.354 & 0.218 & 0.550 \\
\hline Export markup shock & $\sigma_{\lambda^{x}}$ & inv. gamma & 0.300 & 2 & 0.977 & 0.214 & 1.124 & 0.772 & 1.604 \\
\hline Monetary policy shock & $\sigma_{R}$ & inv. gamma & 0.150 & 2 & 0.133 & 0.013 & 0.135 & 0.113 & 0.160 \\
\hline Inflation target shock & $\sigma_{\bar{\pi}_{-}^{c}}$ & inv. gamma & 0.050 & 2 & 0.044 & 0.012 & 0.053 & 0.032 & 0.081 \\
\hline Interest rate smoothing & $\rho_{R}$ & beta & 0.800 & 0.050 & 0.874 & 0.021 & 0.881 & 0.844 & 0.915 \\
\hline Inflation response & $r_{\pi}$ & normal & 1.700 & 0.100 & 1.710 & 0.067 & 1.730 & 1.577 & 1.876 \\
\hline Diff. infl response & $r_{\Delta \pi}$ & normal & 0.300 & 0.100 & 0.317 & 0.059 & 0.310 & 0.212 & 0.411 \\
\hline Real exch. rate response & $r_{x}$ & normal & 0.000 & 0.050 & -0.009 & 0.008 & -0.009 & -0.024 & 0.006 \\
\hline Output response & $r_{y}$ & normal & 0.125 & 0.050 & 0.078 & 0.028 & 0.104 & 0.051 & 0.168 \\
\hline Diff. output response & $r_{\Delta \pi}$ & normal & 0.0625 & 0.050 & 0.116 & 0.028 & 0.128 & 0.081 & 0.177 \\
\hline Log marginal likelihood & & & & & & & -1909.34 & & \\
\hline
\end{tabular}

Note: For the inverse gamma distribution, the mode and the degrees of freedom are reported. Also, for the parameters $\lambda^{d}, \lambda^{m c}, \lambda^{m i}, \eta_{i}, \eta_{f}$ and $\mu_{z}$ the prior distributions are truncated at 1 . A posterior sample of 550,000 draws was generated from the posterior of which the first 50,000 draws were discarded as burn-in. Convergence was checked using standard diagnostics such as CUSUM plots and ANOVA on parallel simulation sequences. 
Table 2: Policy parameters from sequential estimations (posterior mode estimates)

\begin{tabular}{|c|c|c|c|c|c|c|c|c|c|c|}
\hline \multirow{2}{*}{ Parameter } & & \multicolumn{9}{|c|}{ End-of-sample period } \\
\hline & & 1993Q4 & 1994Q4 & 1995Q4 & 1996Q4 & 1997Q4 & 1998Q4 & 1999Q4 & 2000Q4 & 2001Q4 \\
\hline Interest rate smoothing & $\rho_{R}$ & $\begin{array}{c}0.790 \\
(0.031)\end{array}$ & $\begin{array}{c}0.799 \\
(0.032)\end{array}$ & $\begin{array}{c}0.826 \\
(0.029)\end{array}$ & $\begin{array}{c}0.835 \\
(0.028)\end{array}$ & $\begin{array}{c}0.863 \\
(0.025)\end{array}$ & $\begin{array}{c}0.891 \\
(0.017)\end{array}$ & $\begin{array}{c}0.888 \\
(0.017)\end{array}$ & $\begin{array}{c}0.896 \\
(0.016)\end{array}$ & $\begin{array}{c}0.881 \\
(0.019)\end{array}$ \\
\hline Inflation response & $r_{\pi}$ & $\begin{array}{c}1.750 \\
(0.082)\end{array}$ & $\begin{array}{c}1.735 \\
(0.074)\end{array}$ & $\begin{array}{c}1.721 \\
(0.088)\end{array}$ & $\begin{array}{c}1.706 \\
(0.072)\end{array}$ & $\begin{array}{c}1.700 \\
(0.091)\end{array}$ & $\begin{array}{c}1.716 \\
(0.060)\end{array}$ & $\begin{array}{c}1.713 \\
(0.091)\end{array}$ & $\begin{array}{c}1.713 \\
(0.091)\end{array}$ & $\begin{array}{c}1.726 \\
(0.076)\end{array}$ \\
\hline Diff. infl response & $r_{\Delta \pi}$ & $\begin{array}{c}0.314 \\
(0.068\end{array}$ & $\begin{array}{c}0.306 \\
(0.069)\end{array}$ & $\begin{array}{c}0.289 \\
(0.068)\end{array}$ & $\begin{array}{c}0.268 \\
(0.065)\end{array}$ & $\begin{array}{c}0.264 \\
(0.064)\end{array}$ & $\begin{array}{c}0.245 \\
(0.060)\end{array}$ & $\begin{array}{c}0.253 \\
(0.059)\end{array}$ & $\begin{array}{c}0.256 \\
(0.057)\end{array}$ & $\begin{array}{c}0.305 \\
(0.058)\end{array}$ \\
\hline Real exch. rate response & $r_{x}$ & $\begin{array}{l}-0.027 \\
(0.008)\end{array}$ & $\begin{array}{l}-0.030 \\
(0.009)\end{array}$ & $\begin{array}{l}-0.034 \\
(0.009)\end{array}$ & $\begin{array}{l}-0.033 \\
(0.008)\end{array}$ & $\begin{array}{l}-0.027 \\
(0.009)\end{array}$ & $\begin{array}{l}-0.012 \\
(0.006)\end{array}$ & $\begin{array}{l}-0.016 \\
(0.006)\end{array}$ & $\begin{array}{l}-0.018 \\
(0.007)\end{array}$ & $\begin{array}{l}-0.023 \\
(0.008)\end{array}$ \\
\hline Output response & $r_{y}$ & $\begin{array}{c}0.092 \\
(0.021)\end{array}$ & $\begin{array}{c}0.116 \\
(0.024)\end{array}$ & $\begin{array}{c}0.114 \\
(0.026)\end{array}$ & $\begin{array}{c}0.123 \\
(0.025) \\
\end{array}$ & $\begin{array}{c}0.121 \\
(0.035) \\
\end{array}$ & $\begin{array}{c}0.042 \\
(0.015) \\
\end{array}$ & $\begin{array}{c}0.042 \\
(0.014) \\
\end{array}$ & $\begin{array}{c}0.046 \\
(0.015) \\
\end{array}$ & $\begin{array}{c}0.069 \\
(0.024) \\
\end{array}$ \\
\hline Diff. output response & $r_{\Delta \pi}$ & $\begin{array}{c}0.131 \\
(0.032)\end{array}$ & $\begin{array}{c}0.146 \\
(0.031)\end{array}$ & $\begin{array}{c}0.149 \\
(0.030)\end{array}$ & $\begin{array}{c}0.145 \\
(0.028)\end{array}$ & $\begin{array}{c}0.143 \\
(0.028)\end{array}$ & $\begin{array}{c}0.164 \\
(0.025)\end{array}$ & $\begin{array}{c}0.159 \\
(0.024)\end{array}$ & $\begin{array}{c}0.164 \\
(0.023)\end{array}$ & $\begin{array}{c}0.134 \\
(0.028)\end{array}$ \\
\hline
\end{tabular}

Note: The estimation starts out in 1980Q1 in all cases. The approximative posterior standard deviation from the Hessian at the posterior mode is reported in parenthesis. 
Figure 1a: Impulse responses from different estimation periods
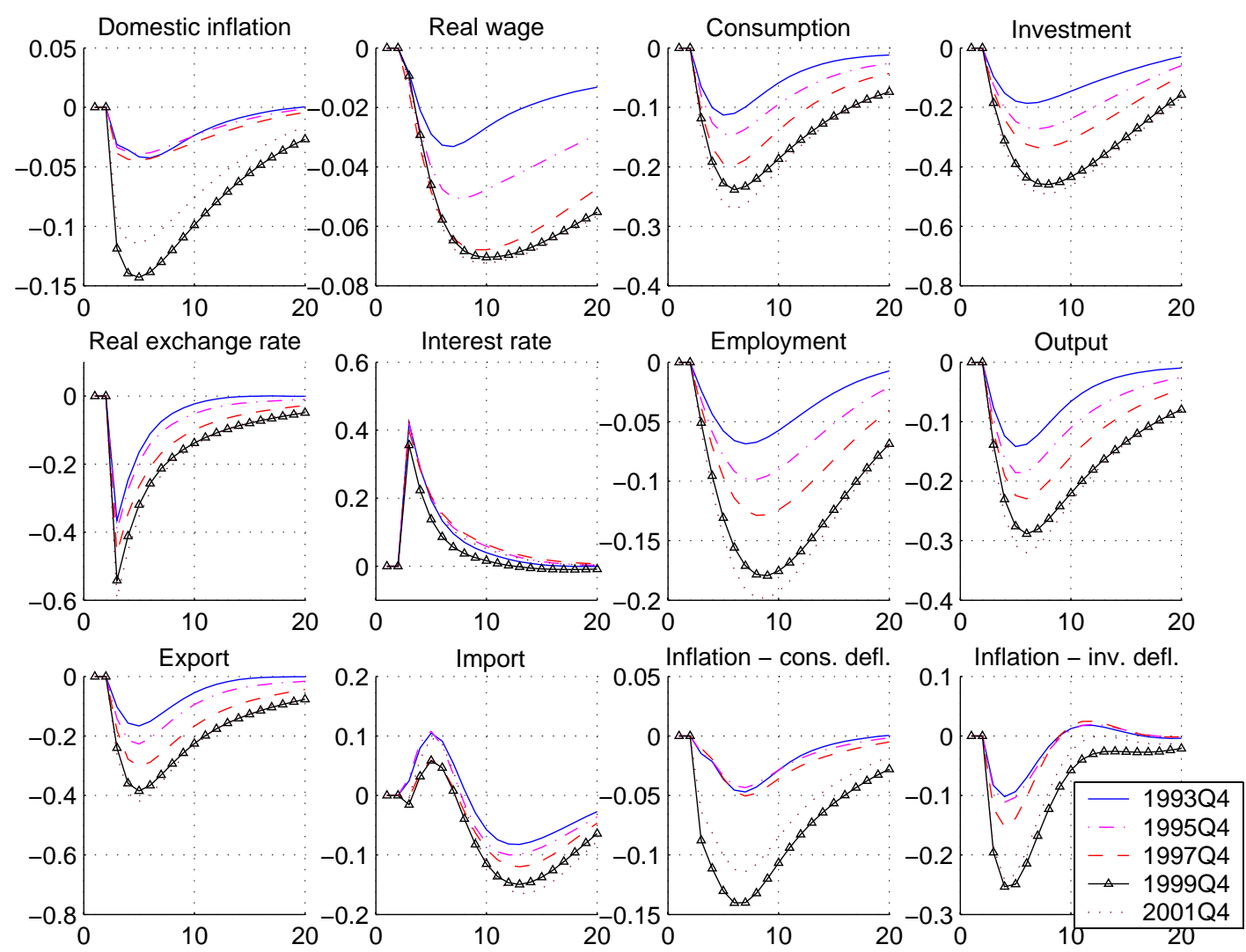
Figure1b: Impulse responses from different policy parameters
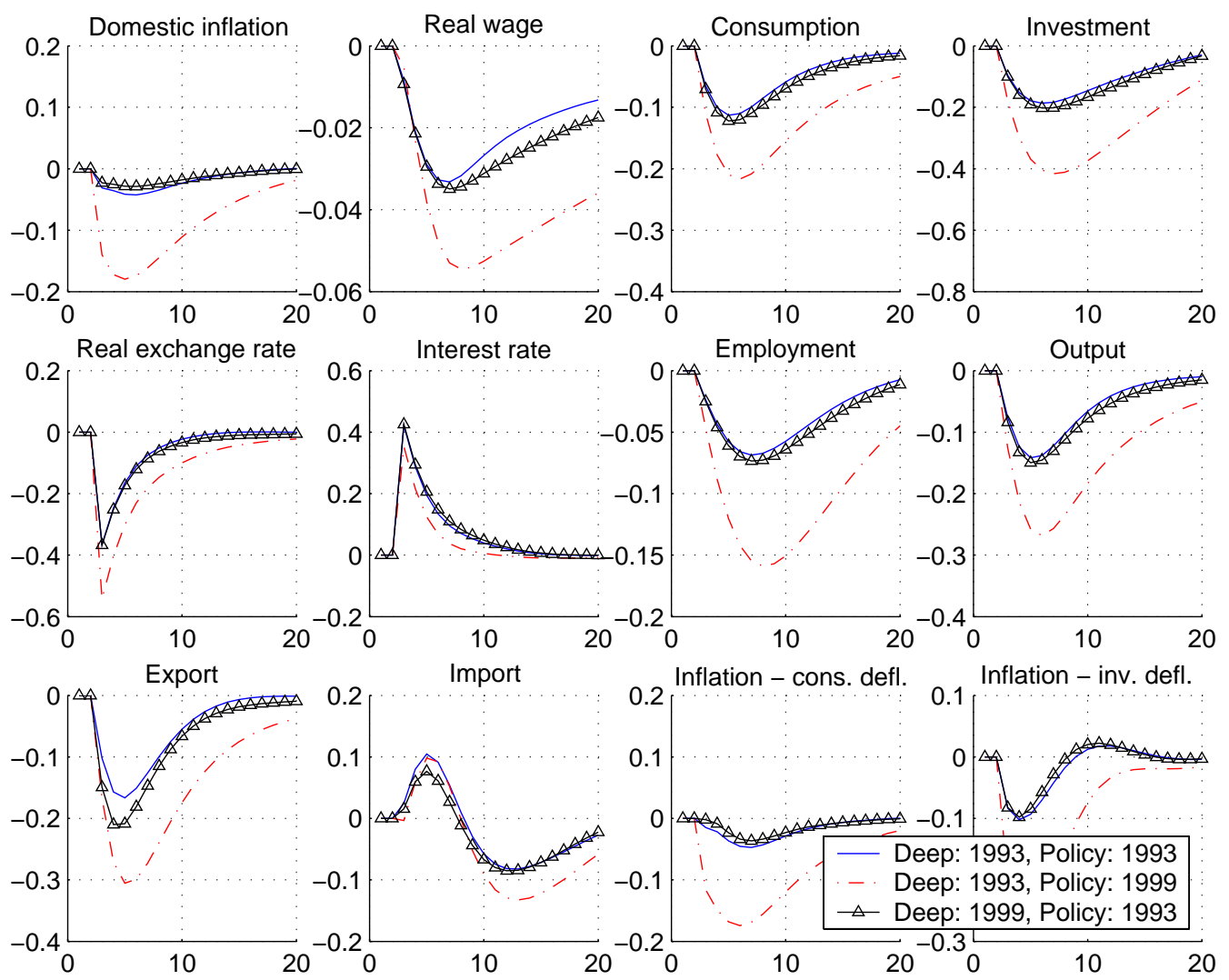
Figure 2a: Univariate modesty statistics with only monetary policy shock uncertainty (Leeper-Zha)
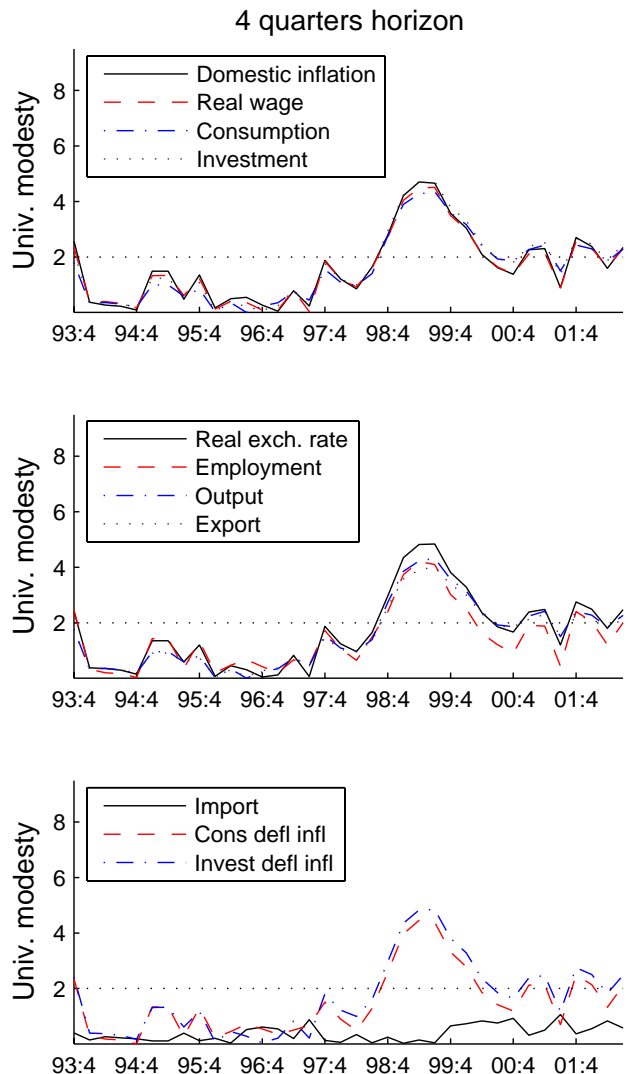

8 quarters horizon
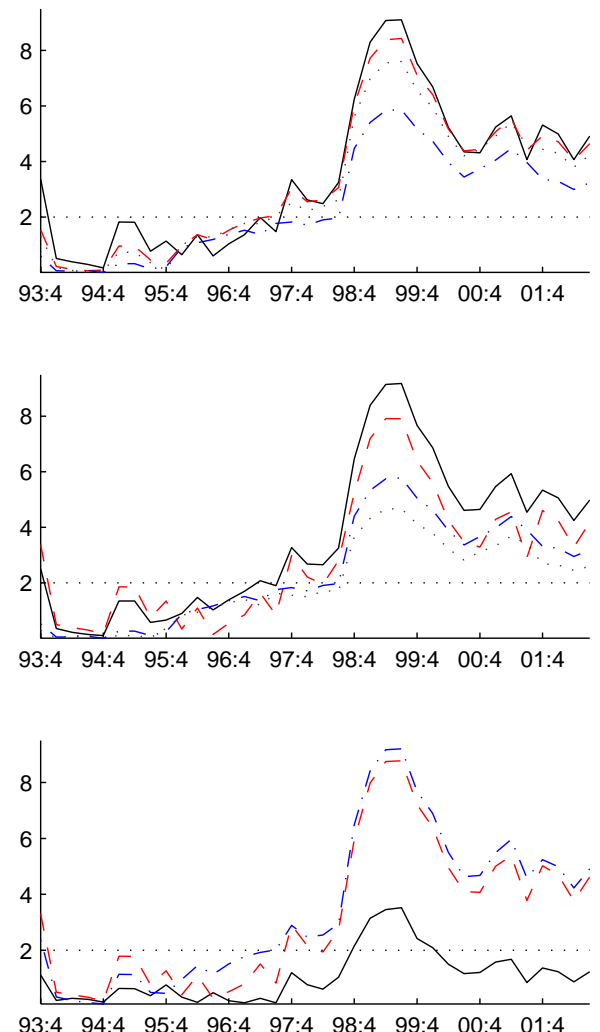
Figure 2b: Univariate modesty statistics with uncertainty about all shocks
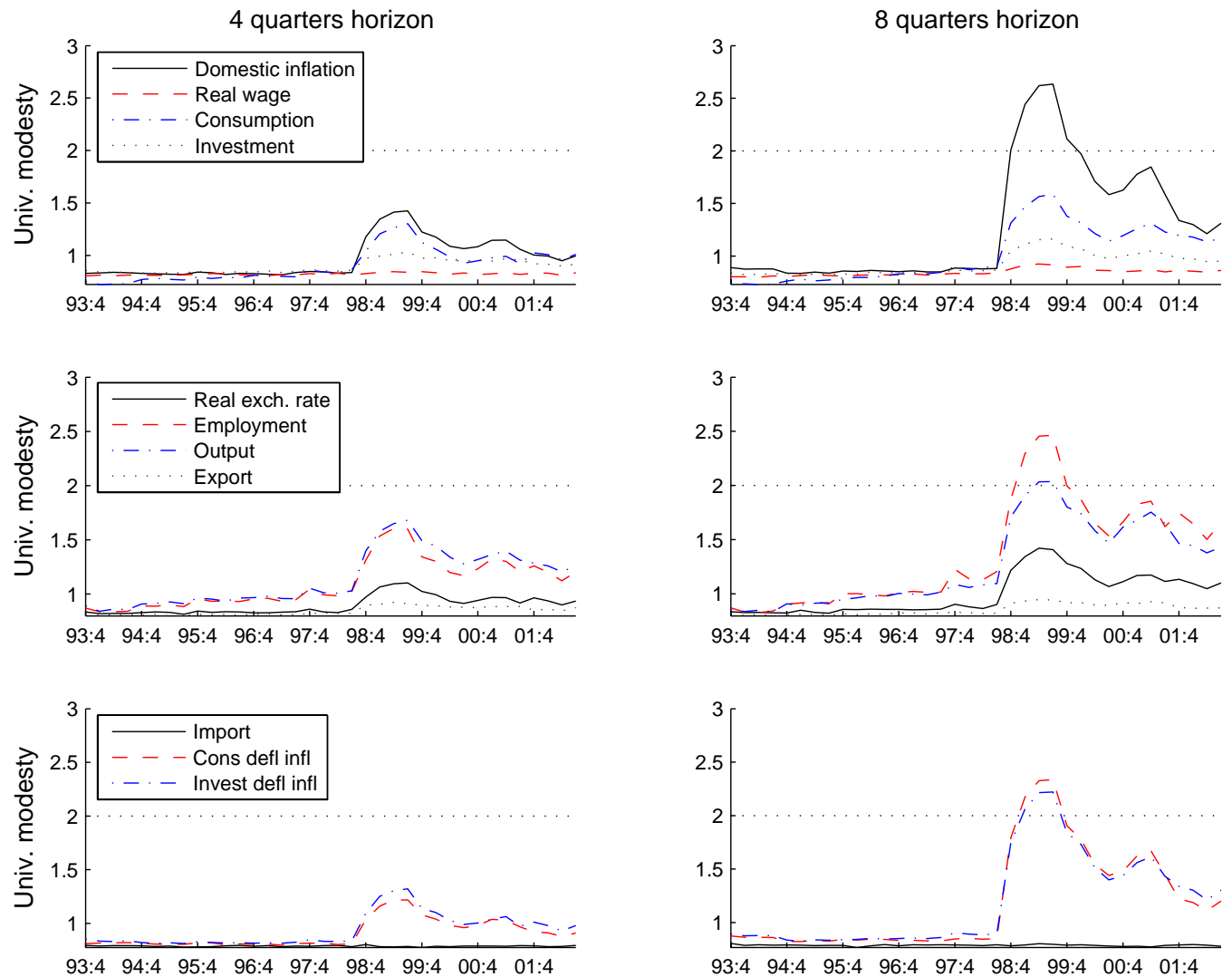
Figure 2c: Multivariate modesty statistic with uncertainty about all shocks (left column: four quarters, right column: eight quarters)
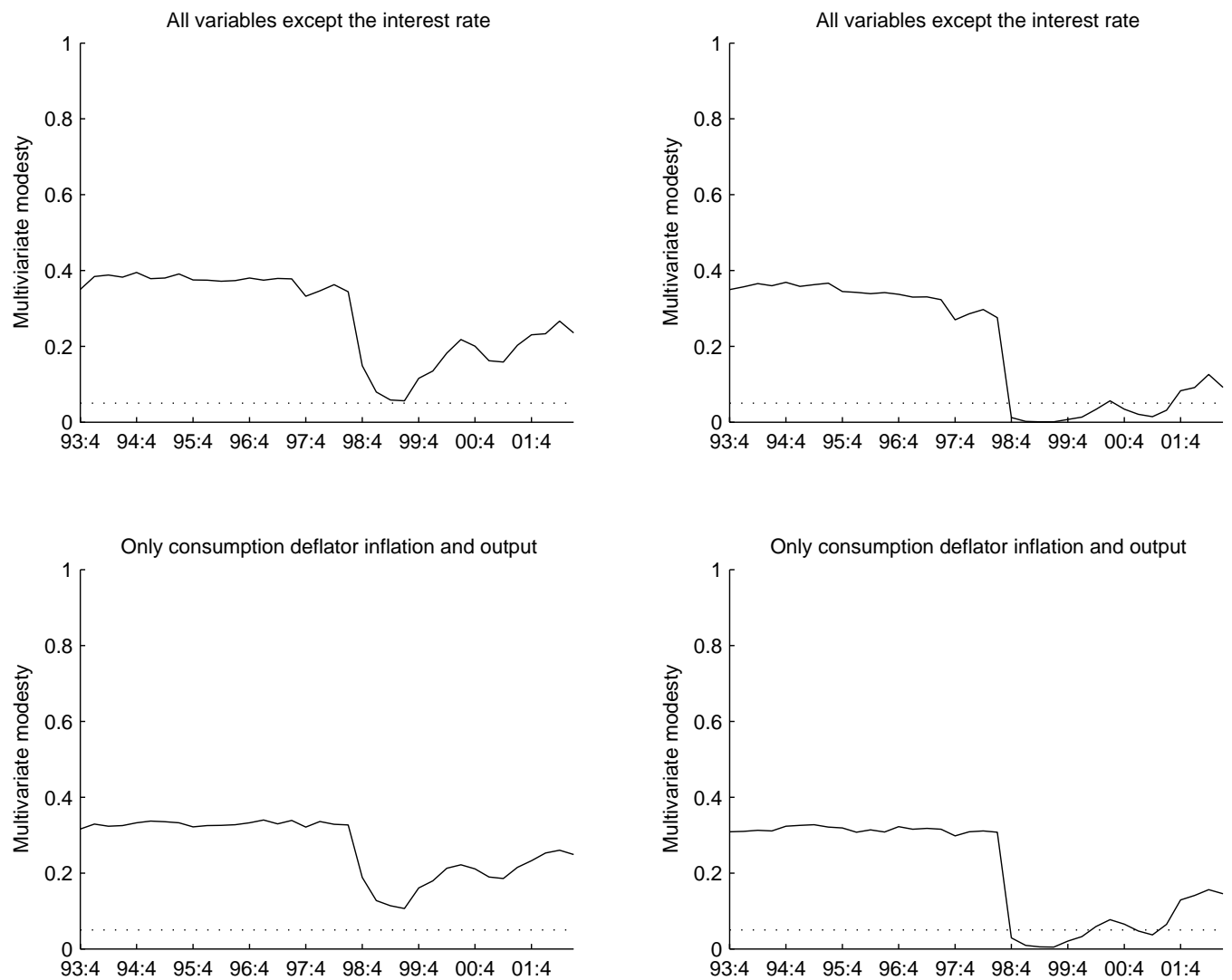
Figure 3a: Unconditional and conditional forecasts in 1999Q2, with only monetary policy shock uncertainty (Leeper-Zha)
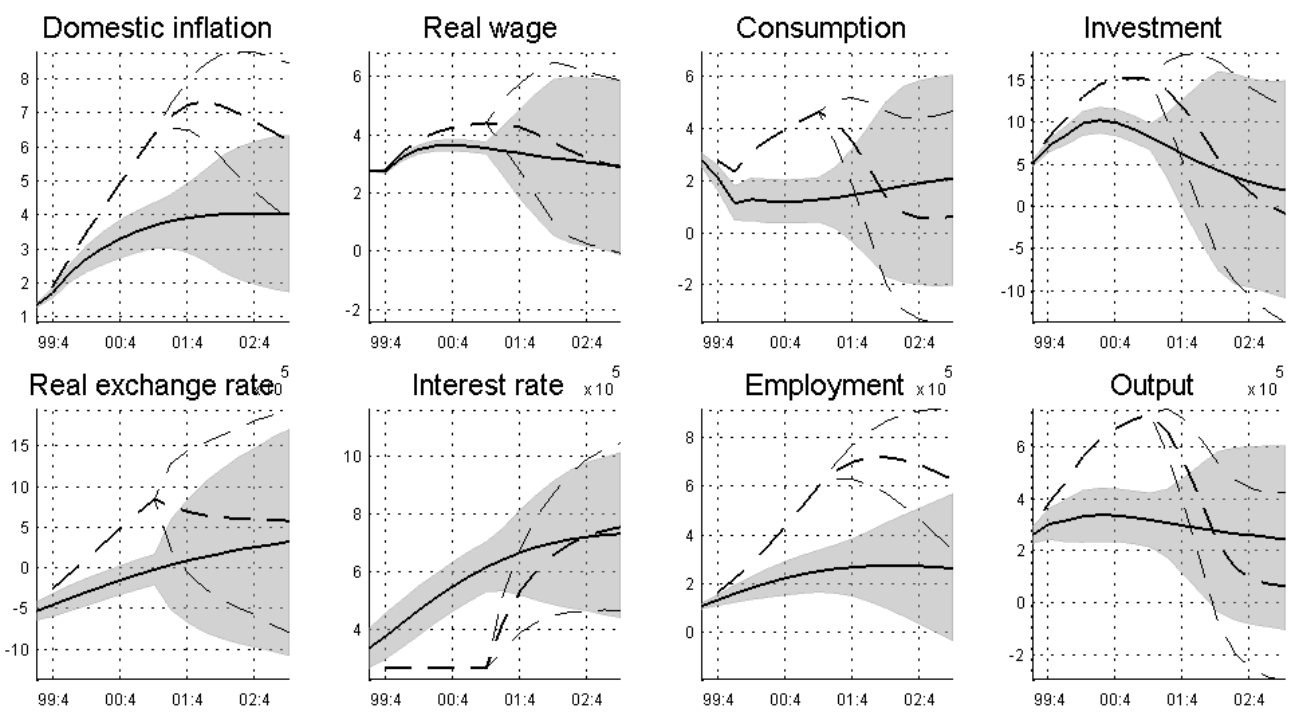

Interest rate $\times 10^{5}$
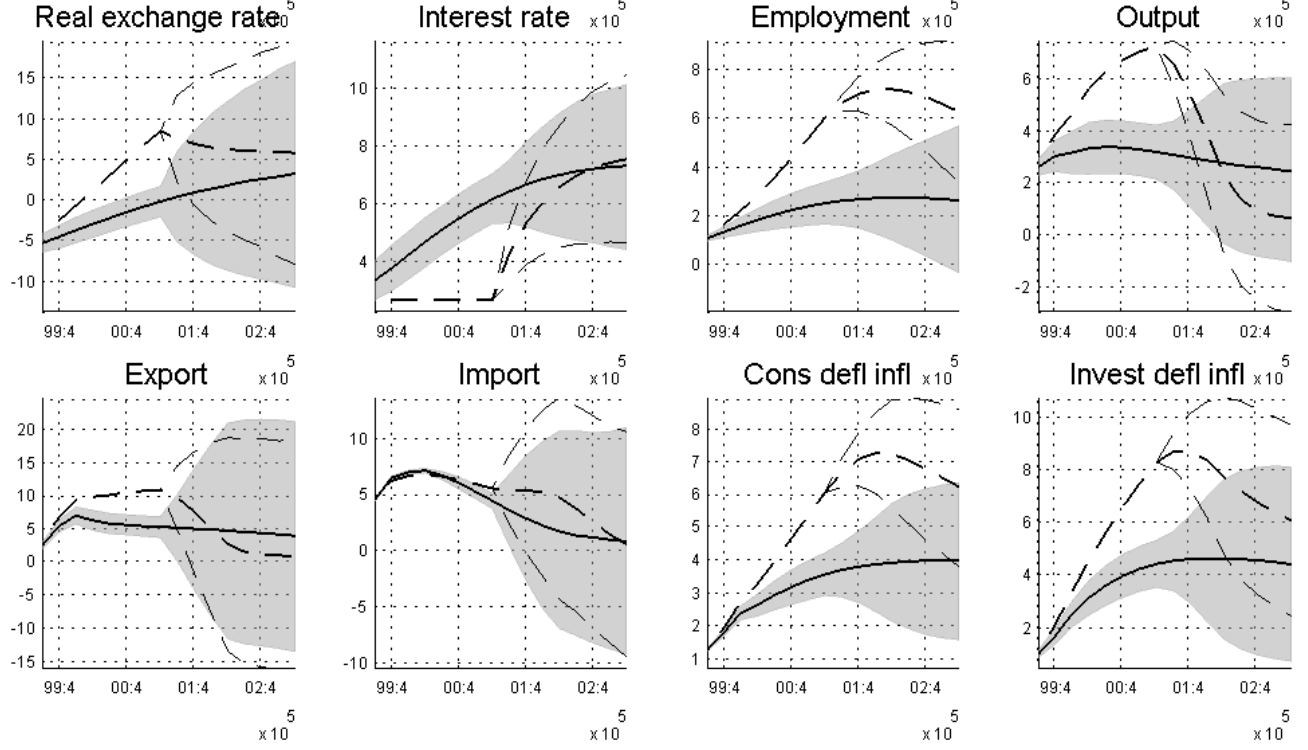
Figure 3b: Unconditional and conditional forecasts in 1999Q2, with uncertainty about all shocks
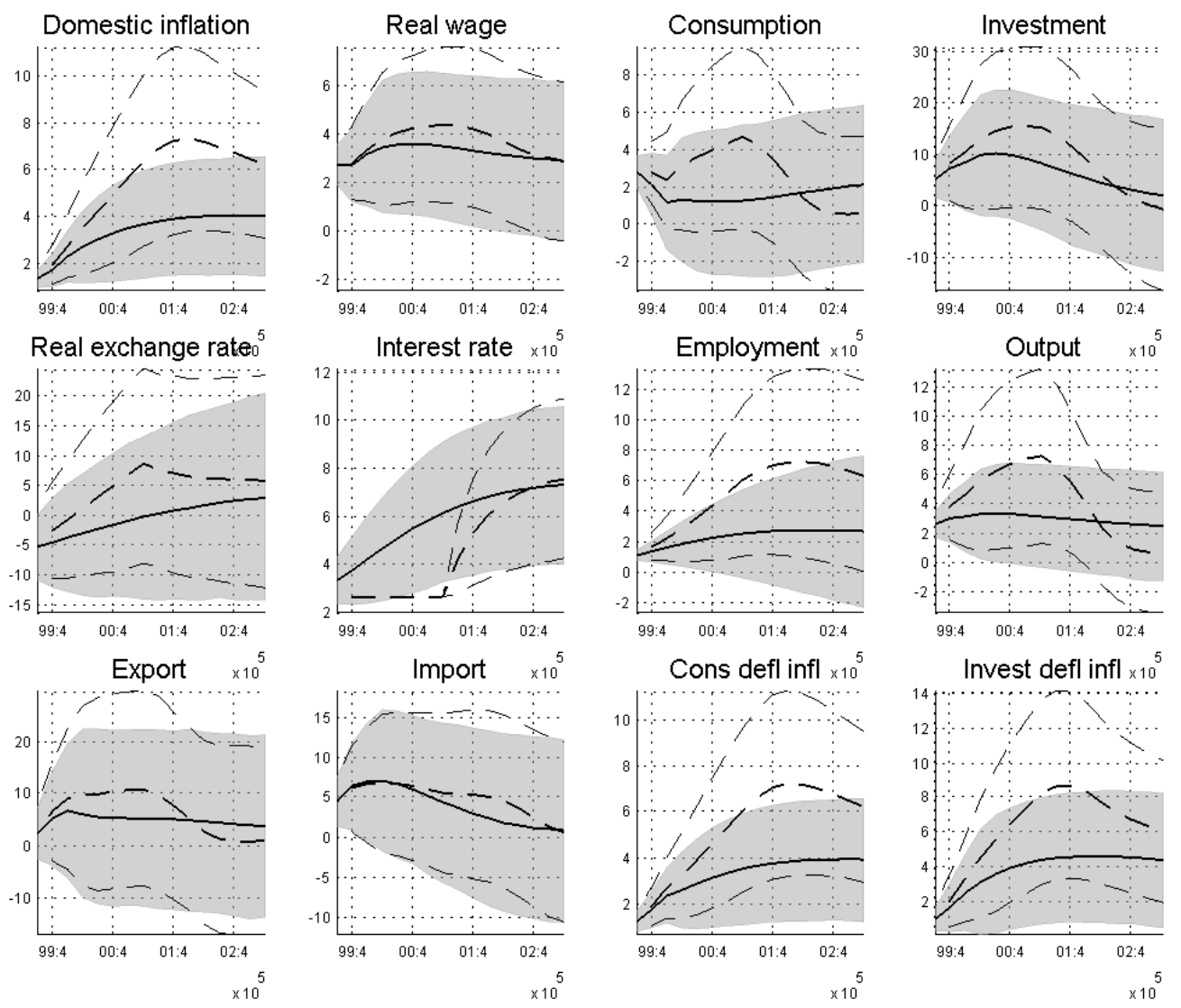
Figure 4a: Unconditional and conditional forecasts in 2001Q1, with only monetary policy shock uncertainty (Leeper-Zha)
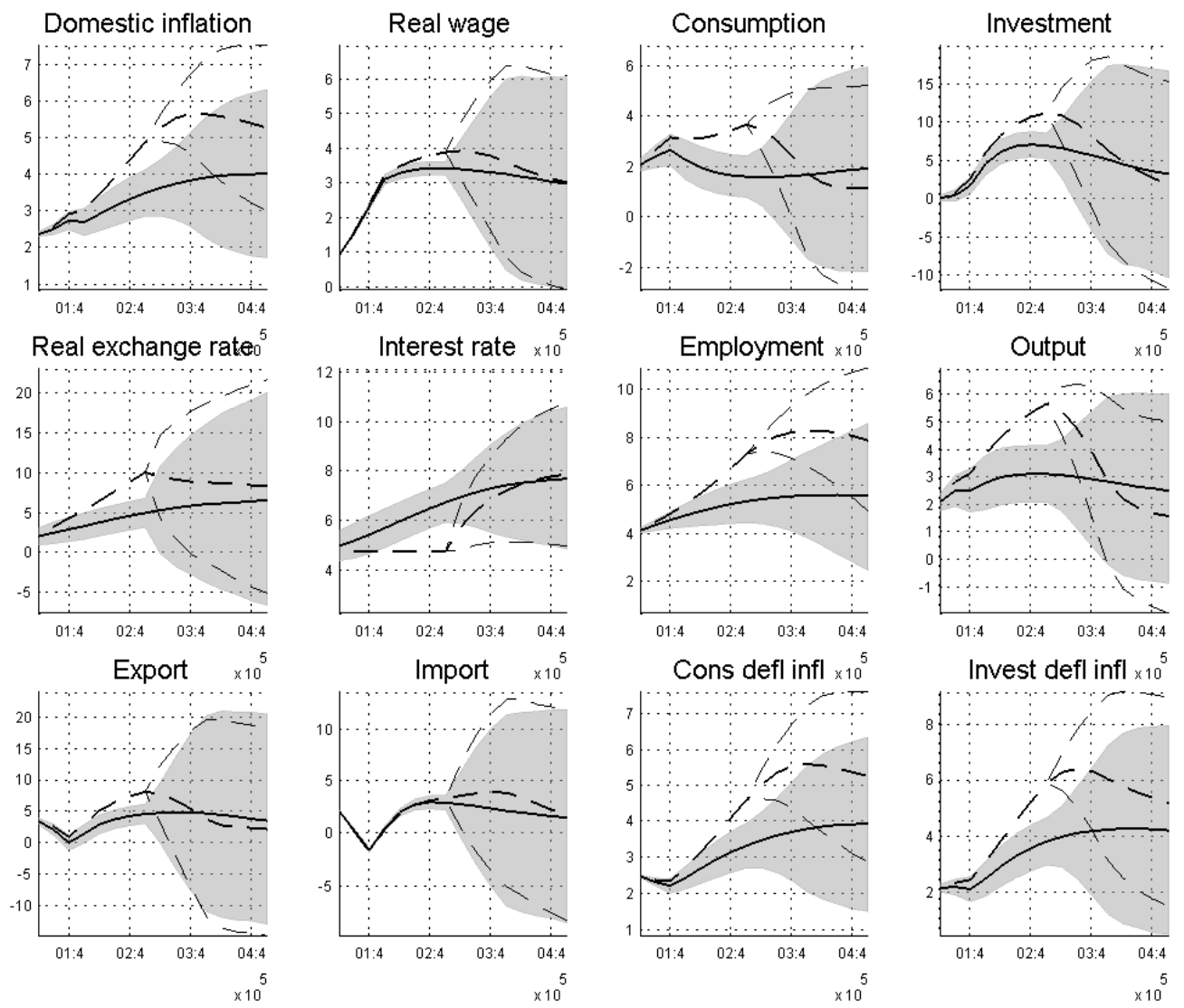
Figure 4b: Unconditional and conditional forecasts in 2001Q1, with uncertainty about all shocks
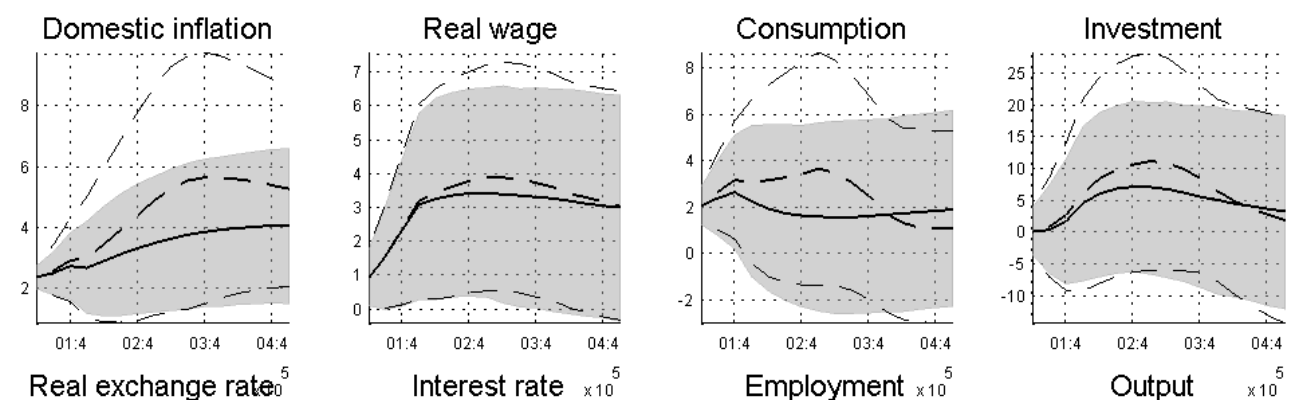

Real exchange rate ${ }^{5}$

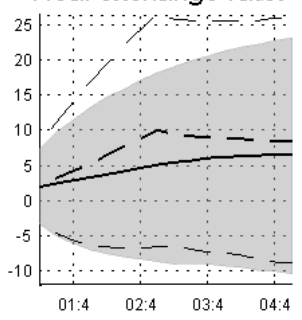

Interest rate $\times 10^{5}$
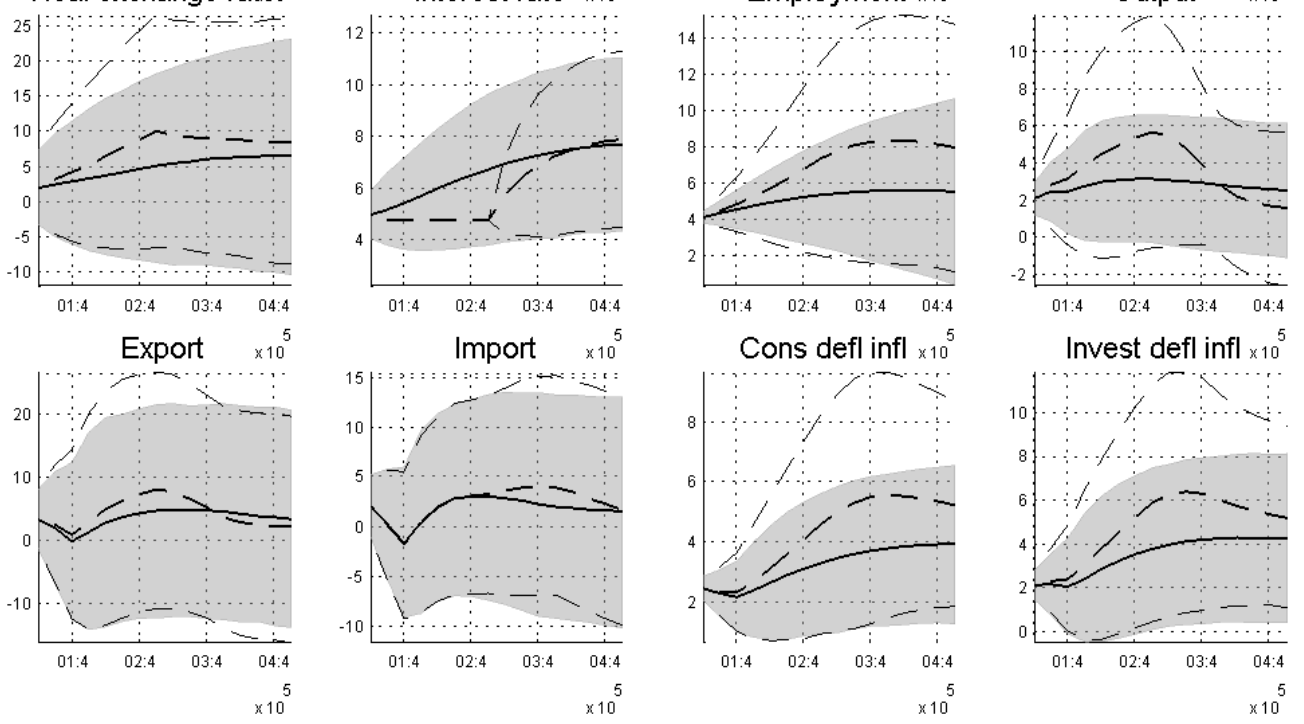